Biotechnology for Biofuels

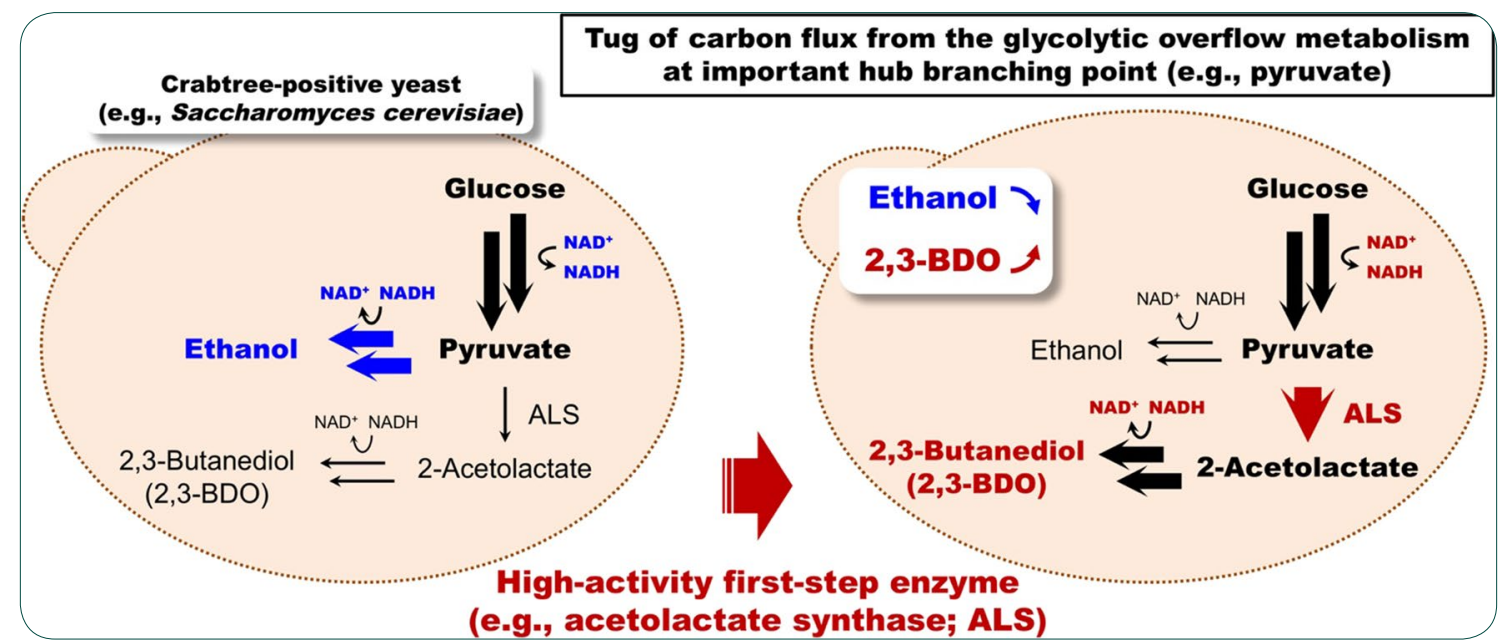

\title{
A pyruvate carbon flux tugging strategy for increasing 2,3-butanediol production and reducing ethanol subgeneration in the yeast Saccharomyces cerevisiae
}

Ishii et al. 


\title{
A pyruvate carbon flux tugging strategy for increasing 2,3-butanediol production and reducing ethanol subgeneration in the yeast Saccharomyces cerevisiae
}

Jun Ishii ${ }^{1 *}$, Keisuke Morita ${ }^{2}$, Kengo Ida ${ }^{3}$, Hiroko Kato ${ }^{1,2}$, Shohei Kinoshita ${ }^{2}$, Shoko Hataya ${ }^{1}$, Hiroshi Shimizu ${ }^{2}$, Akihiko Kondo ${ }^{1,3,4}$ and Fumio Matsuda ${ }^{2,4^{*}}$

\begin{abstract}
Background: The yeast Saccharomyces cerevisiae is a promising host cell for producing a wide range of chemicals. However, attempts to metabolically engineer Crabtree-positive S. cerevisiae invariably face a common issue: how to reduce dominant ethanol production. Here, we propose a yeast metabolic engineering strategy for decreasing ethanol subgeneration involving tugging the carbon flux at an important hub branching point (e.g., pyruvate). Tugging flux at a central glycolytic overflow metabolism point arising from high glycolytic activity may substantially increase higher alcohol production in S. cerevisiae. We validated this possibility by testing 2,3-butanediol (2,3-BDO) production, which is routed via pyruvate as the important hub compound.
\end{abstract}

Results: By searching for high-activity acetolactate synthase (ALS) enzymes that catalyze the important first-step reaction in 2,3-BDO biosynthesis, and tuning several fermentation conditions, we demonstrated that a stronger pyruvate pulling effect (tugging of pyruvate carbon flux) is very effective for increasing 2,3-BDO production and reducing ethanol subgeneration by $S$. cerevisiae. To further confirm the validity of the pyruvate carbon flux tugging strategy, we constructed an evolved pyruvate decarboxylase (PDC)-deficient yeast (PDC $\triangle$ ) strain that lacked three isozymes of PDC. In parallel with re-sequencing to identify genomic mutations, liquid chromatography-tandem mass spectrometry analysis of intermediate metabolites revealed significant accumulation of pyruvate and NADH in the evolved PDC $\triangle$ strain. Harnessing the high-activity ALS and additional downstream enzymes in the evolved PDC $\triangle$ strain resulted in a high yield of 2,3-BDO (a maximum of $0.41 \mathrm{~g} \mathrm{~g}^{-1}$ glucose consumed) and no ethanol subgeneration, thereby confirming the utility of our strategy. Using this engineered strain, we demonstrated a high 2,3-BDO titer $\left(81.0 \mathrm{~g} \mathrm{~L}^{-1}\right)$ in a fed-batch fermentation using a high concentration of glucose as the sole carbon source.

Conclusions: We demonstrated that the pyruvate carbon flux tugging strategy is very effective for increasing 2,3$\mathrm{BDO}$ production and decreasing ethanol subgeneration in Crabtree-positive S. cerevisiae. High activity of the common first-step enzyme for the conversion of pyruvate, which links to both the TCA cycle and amino acid biosynthesis, is likely important for the production of various chemicals by S. cerevisiae.

Keywords: Pyruvate flux, Crabtree effect, Acetolactate synthase, Ethanol subgeneration, 2,3-Butanediol production, Pyruvate decarboxylase (PDC) deficient

\footnotetext{
*Correspondence: junjun@port.kobe-u.ac.jp; fmatsuda@ist.osaka-u.ac.jp

${ }^{1}$ Graduate School of Science, Technology and Innovation, Kobe

University, 1-1 Rokkodai, Nada, Kobe 657-8501, Japan

${ }^{2}$ Department of Bioinformatic Engineering, Graduate School

of Information Science and Technology, Osaka University, 1-5 Yamadaoka,

Suita, Osaka 565-0871, Japan

Full list of author information is available at the end of the article
}

(c) The Author(s) 2018. This article is distributed under the terms of the Creative Commons Attribution 4.0 International License (http://creativecommons.org/licenses/by/4.0/), which permits unrestricted use, distribution, and reproduction in any medium, provided you give appropriate credit to the original author(s) and the source, provide a link to the Creative Commons license, and indicate if changes were made. The Creative Commons Public Domain Dedication waiver (http://creativecommons.org/ publicdomain/zero/1.0/) applies to the data made available in this article, unless otherwise stated. 


\section{Background}

The budding (brewer's or baker's) yeast Saccharomyces cerevisiae is a traditional microorganism used for various industrial applications. Historically, S. cerevisiae has mainly been used for alcohol (ethanol) fermentations (e.g., beer and wine) [1], but the use of this yeast as a microbial cell factory was recently proposed for producing a wide range of chemicals including higher alcohols (e.g., linear or branched alcohols and diols, such as 1-propanol [2], $n$-butanol [3], isobutanol [4] and 1,3-propanediol [5]). To date, the focus has mainly been on the production of 2,3-butanediol (2,3-BDO) [6-9] because it is relatively easy to engineer high-producing yeast strains due to their redox balanced NADH-dependent reductive reaction(s) (Fig. 1a-c) [10], the low toxicity of 2,3-BDO to microbes [11]), and the wide applicability of 2,3-BDO as a platform chemical (Fig. 1d).
2,3-BDO can be directly used as an anti-freeze agent or chemically converted to other chemicals (Fig. 1d) [10, 12]. For example, 1,3-butadiene (1,3-BD) can be produced by the two-step dehydration of 2,3-BDO [13, 14]. $1,3-\mathrm{BD}$ is a feedstock for the generation of synthetic rubber [15], and for the synthesis of hexamethylene diamine and adipic acid [16]. 2,3-BDO can also be converted to methyl ethyl ketone (MEK; butanone), 2-methylpropanal (2-MPA; isobutyraldehyde), and several butene derivatives by dehydration and/or hydrogenation (Fig. 1d). Thus, 2,3-BDO is a promising starting material for the synthesis of various compounds, including resin solvents, fuel additives, and butyl rubber (Fig. 1d) [13, 14, 17, 18].

The metabolic engineering of S. cerevisiae to produce various chemicals generally faces a common challenge: how to reduce dominant ethanol production [19]. In the presence of a high concentration of glucose, S. cerevisiae

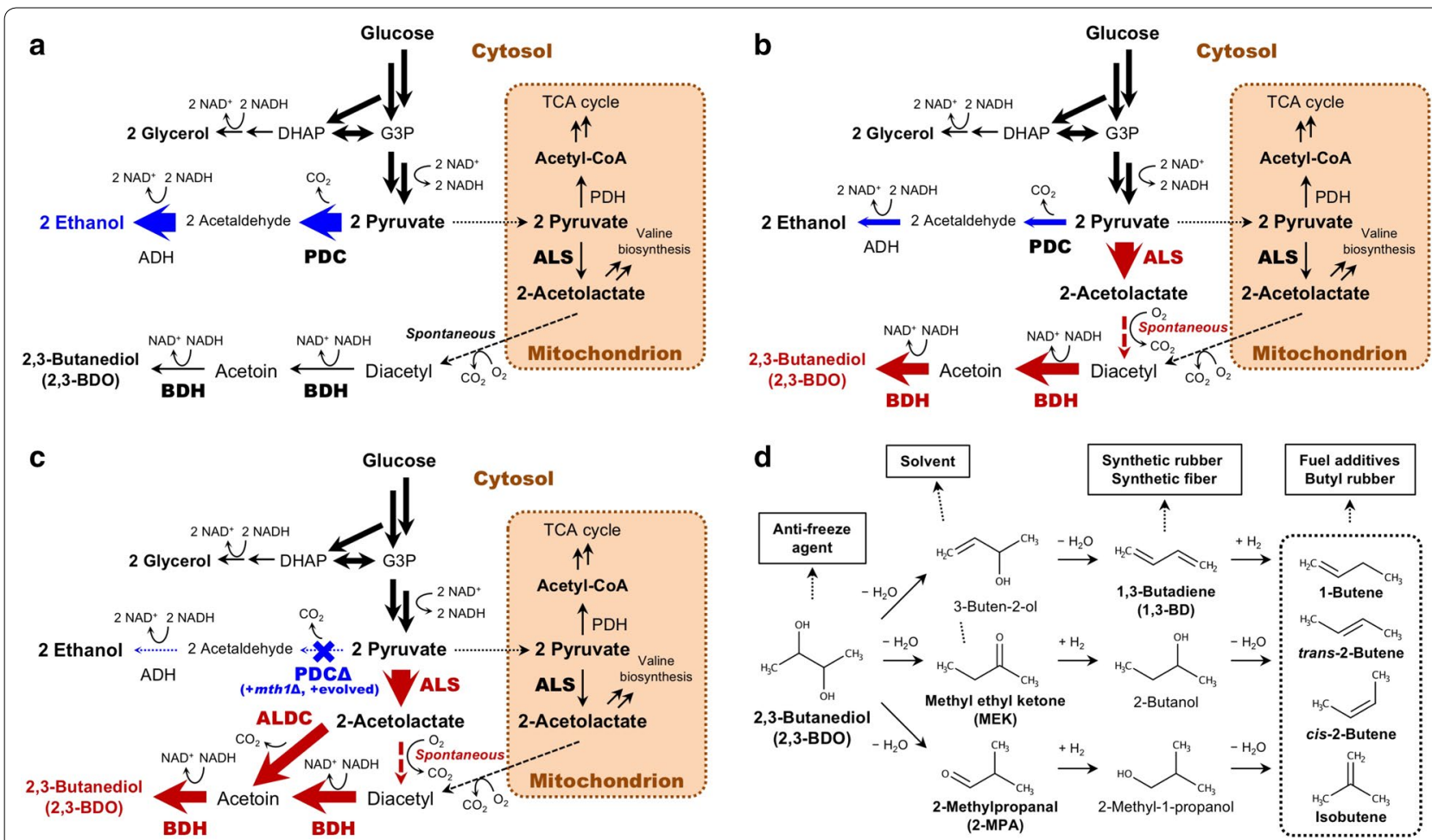

Fig. 1 Pyruvate carbon flux tugging strategies for increased 2,3-butanediol (2,3-BDO) production and reduced ethanol subgeneration in yeast. a Ethanol and 2,3-BDO biosynthetic pathways in the wild-type yeast S. cerevisiae. Yeast preferentially produces ethanol even under aerobic conditions via the "Crabtree effect", which remains to be completely elucidated. However, the strong activities of the glycolytic Embden-Meyerhof-Parnas (EMP) pathway and fermentative ethanol biosynthetic pathway in maintaining the redox homeostasis of NADH likely contribute to the Crabtree effect. Wild-type S. cerevisiae produces a small amount of 2,3-BDO via 2-acetolactate synthesized in the mitochondria. $\mathbf{b}$ Metabolic engineering strategy to tug the pyruvate carbon flux in yeast. High-activity cytosolic (or mitochondrial) acetolactate synthase (ALS) is required for increased 2,3-BDO production and reduced ethanol subgeneration. $\mathbf{c}$ A pyruvate decarboxylase (PDC)-deficient yeast (PDC $\triangle$ ) strain (containing the MTH1- $\triangle T$ allele and subjected to laboratory evolution) was used to further ensure tugging of the pyruvate carbon flux and secure higher 2,3-BDO production. Acetolactate decarboxylase (ALDC) and butanediol dehydrogenase (BDH) were additionally (over)expressed to avoid clogging the carbon flux toward 2,3-BDO biosynthesis. $\mathbf{d}$ Applications of 2,3-BDO and its derivatives. 2,3-BDO can be chemically converted to various chemicals, including synthetic rubbers and fuel additives. G3P glyceraldehyde 3-phosphate, DHAP dihydroxyacetone phosphate, TCA tricarboxylic acid, ADH alcohol dehydrogenase, $P D H$ pyruvate dehydrogenase 
produces ethanol dominantly, even under aerobic conditions, due to a process known as the "Crabtree effect" (Fig. 1a) [20, 21]. Increasing the concentration of glucose reduces the need for oxidative phosphorylation by the tricarboxylic acid (TCA) cycle and accelerates glycolysis as the major source of energy. Although the mechanism of this glycolytic overflow metabolism is not completely understood, it is assumed to involve the redox homeostasis of NADH between the glycolytic and fermentative (ethanol) pathways [20,21], in which a net of two NADH molecules are generated from one glucose molecule via glycolysis and subsequently oxidized in the ethanol formation reaction [22]) (Fig. 1a). It has been experimentally demonstrated that increased NADH oxidation can reduce ethanol formation [23]. Additionally, an in silico metabolic simulation suggested that the greater difficulty in metabolically engineering the eukaryote $S$. cerevisiae to produce higher alcohol concentrations compared to the prokaryote Escherichia coli is due to the structurally limited flexibility of the central metabolism and mitochondrial compartmentation of eukaryotes [24].

The NADH-dependent reductive reaction(s) may provide a strategy for using the 2,3-BDO biosynthesis pathway to displace the ethanol biosynthesis pathway (Fig. 1a) $[10,19]$. In wild-type $S$. cerevisiae, 2 -acetolactate is synthesized by the endogenous acetolactate synthase (ALS) Ilv2p, which localizes to the mitochondria and catalyzes the conversion of pyruvate (Fig. 1a) [12, 25]. Spontaneous decarboxylation can convert 2-acetolactate into diacetyl in the presence of oxygen. Next, diacetyl can be converted in the yeast cytosol into acetoin and 2,3-BDO via the NADH-dependent two-step reductive reactions of butanediol dehydrogenase (BDH; EC 1.1.1.4), an enzyme that also has diacetyl reductase activity and is encoded by the $B D H 1$ (or $B D H 2$ ) gene in S. cerevisiae (Fig. 1a) [12]. In contrast, many bacteria synthesize 2 -acetolactate in the cytosol (Fig. 1b) and then convert it into acetoin via two routes: (1) a two-step conversion by spontaneous decarboxylation and an NADH-dependent diacetyl reductase reaction (Fig. 1b), or (2) an enzymatic onestep conversion by acetolactate decarboxylase (ALDC) (Fig. 1c) [12]. Similar to S. cerevisiae, bacteria also further convert acetoin into 2,3-BDO by an NADH-dependent $\mathrm{BDH}$ reductive reaction [12]. Although redox balance is not completely maintained in the bacterial ALDC reaction, moderate production of 2,3-BDO is possible.

To achieve increased production of higher alcohols and reduced subgeneration of ethanol in Crabtree-positive $S$. cerevisiae, in this study we investigated the utility of tugging high glycolytic carbon flux into 2,3-BDO biosynthesis by introducing a stronger pulling effect at the hub branching point (pyruvate) (Fig. 1b). For this purpose, we searched gene databases for a high-activity
ALS enzyme and confirmed the effectiveness of the identified enzyme for increasing 2,3-BDO production and reducing ethanol subgeneration. We demonstrated the validity of our strategy by constructing a pyruvate decarboxylase (PDC)-deficient yeast (PDC $\Delta$ ) strain and conducted experimental evolution to improve its growth rate (Fig. 1c). In parallel with genome re-sequencing for identifying mutations, we conducted liquid chromatography-tandem mass spectrometry (LC-MS/MS) analysis of the intermediate metabolites. This analysis revealed significant accumulation of pyruvate and NADH in the evolved PDC $\Delta$ strain. The combination of the high-activity ALS and the manipulation of additional downstream enzymes for 2,3-BDO biosynthesis into this evolved PDC $\Delta$ strain provided a high yield of 2,3-BDO (a maximum of $0.41 \mathrm{~g} \mathrm{~g}^{-1}$ glucose consumed, the highest value reported to date for $S$. cerevisiae $[12,26])$. Using this engineered strain, we tuned the fermentation conditions and achieved a quite high 2,3-BDO titer $\left(81.0 \mathrm{~g} \mathrm{~L}^{-1}\right)$ in fed-batch fermentations using a high concentration of glucose as the sole carbon source.

\section{Methods}

\section{Yeast strains and media}

Details of the S. cerevisiae strain YPH499 [27] (Stratagene/Agilent Technologies, Palo Alto, CA, USA) and other recombinant strains used in this study and their genotypes are outlined in Table 1.

Full details of the culture media are described in Additional file 3: Method S1. Briefly, yeast-peptone-dextrose-adenine (YPDA), minimal synthetic dextrose (SD), and synthetic complete (SC) media containing $20 \mathrm{~g} \mathrm{~L}^{-1}$ glucose were used. For fermentation tests, SD medium contained a high concentration of glucose $(25,50$ or $100 \mathrm{~g} \mathrm{~L}^{-1}$ ) as the sole carbon source. Amino acids and nucleotides were supplemented as necessary because SD selection medium lacks these auxotrophic components.

\section{Yeast strain construction}

Full details of the construction of the gene deletion mutants are described in Additional file 3: Method S2 and are shown in Additional file 1: Fig. S1. All yeast strains used in this study were generated from the YPH499 parental strain [27] and are listed in Table 1. All primers used for the construction of the yeast gene deletion mutants are listed in Additional file 2: Table S1. Using YPH499 as the parental strain, a quadruple deletion mutant (MTH1- $\Delta T$ pdc1 $\Delta p d c 5 \Delta p d c 6 \Delta$ ) YSM021 strain (PDC $\Delta$ strain) (Table 1) was constructed using the seamless marker recycling method (URA-blaster method) [28]. 
Table 1 Yeast strains used in this study

\begin{tabular}{|c|c|c|}
\hline Strain & Genotypes & Source \\
\hline YPH499 & MATa ura3-52 lys2-801 ade2-101 trp1- $\triangle 63$ his3- $\triangle 200$ leu2- $\Delta 1$ & {$[27]$} \\
\hline YJI2 & YPH499 pdc5 $\Delta$ & This study \\
\hline Yנl6 & YPH499 pdc5 $\triangle p d c 6 \Delta$ & This study \\
\hline YSM009 & YPH499 pdc5 $\triangle p d c 6 \triangle M T H 1-\triangle T$ (genome sequence was not determined) & This study \\
\hline YSM021 (PDCA) & YPH499 pdc1 $\triangle p d c 5 \Delta p d c 6 \triangle M T H 1-\triangle T(L 165 F)$ & This study \\
\hline Evo44 & Obtained from YSM021 by laboratory evolution in SD medium (culture series 1) for 44 days & This study \\
\hline Evo44-1 & Colony \#1 isolated from Evo44 glycerol stock & This study \\
\hline Evo44-2 & Colony \#2 isolated from Evo44 glycerol stock & This study \\
\hline Evo44-3 & Colony \#3 isolated from Evo44 glycerol stock & This study \\
\hline Evo122 & Obtained from YSM021 by laboratory evolution in SD medium (culture series 1) for 122 days & This study \\
\hline Evo122-1 & Colony \#1 isolated from Evo122 glycerol stock & This study \\
\hline Evo122-2 & Colony \#2 isolated from Evo122 glycerol stock & This study \\
\hline Evo122-3 & Colony \#3 isolated from Evo122 glycerol stock & This study \\
\hline YSM046 (PDC $\triangle+$ evolved) & Identical to Evo122-2: a laboratory-evolved yeast strain derived from PDC $\triangle$ (YSM021) strain & This study \\
\hline
\end{tabular}

\section{Plasmid construction and yeast transformation}

Full details regarding plasmid construction and yeast transformation are described in Additional file 3: Method S3. All plasmids used in this study are listed in Table 2. All primers used for plasmid construction are listed in Additional file 2: Table S1. The transformation of plasmid DNA was carried out using the lithium acetate method [29]. All transformants generated in this study are listed in Table 3.

\section{Laboratory evolution}

Full details of the laboratory evolution experiments are described in Additional file 3: Method S4. For laboratory evolution of the PDCA (YSM021) strain (Table 1), a passage culture in SD medium was carried out with five independent culture series. Cells of culture series 1 at days 44 and 122 (Evo44 and Evo122 strains) (Table 1) were stored as glycerol stocks. An isolate of Evo122 (Evo122-2) was designated the YSM046 strain (evolved PDC $\Delta$ strain) (Table 1).

\section{Genome re-sequencing}

Full details of the genome re-sequencing experiments are described in Additional file 3: Method S5. The whole genomes of YPH499, YSM021, and six evolved strains were sequenced by pair-end sequencing (250 bp) using an Illumina HiSeq2000 next-generation sequencer and a MiSeq reagent 500 cycle kit v2 (Illumina, San Diego, CA, USA), then analyzed with Bowtie2 [30], SAMtools [31], and Integrative Genomics Viewer (IGV) [32] software.

\section{Relative activity measurements of acetolactate synthase (ALS) enzymes}

Full details of the ALS enzyme assays are described in Additional file 3: Method S6). Yeast cells were grown in SD selection medium and then the collected cells were disrupted with glass beads using a Shake Master Neo (Bio Medical Science, Tokyo, Japan) to obtain cell crude extracts. The ALS activity assay basically followed previously described procedures [33, 34]. Briefly, a pre-mixture containing thiamine pyrophosphate, FAD, $\mathrm{MgCl}_{2}$ and crude yeast cell extract was pre-incubated, and then the reaction was started by adding pyruvate. The reaction was stopped by adding sulfonic acid and the reaction mixture was incubated to convert 2-acetolactate to acetoin. Acetoin was then further oxidized to diacetyl with creatine and $\alpha$-naphthol. The relative ALS activity based on the colorimetric assay of acetoin (or diacetyl) was determined by measuring the absorbance (at $525 \mathrm{~nm}$ ) of the developed red color using an EnVision multilabel plate reader (Perkin Elmer, Waltham, MA, USA).

\section{Culture conditions}

Full details of the culture conditions are described in Additional file 3: Method S7. Yeast cells were seeded at a low initial optical density (OD) and grown or used for fermentation in SD or SD selection media containing $20 \mathrm{~g} \mathrm{~L}^{-1}$ glucose at $30{ }^{\circ} \mathrm{C}$. The fermentation conditions of the YHI030 strain (Table 2) were tuned by inoculating the pre-cultured cells into $50 \mathrm{~mL}$ of fresh $\mathrm{SD}$ selection medium (containing either 25, 50 or $100 \mathrm{~g} \mathrm{~L}^{-1}$ glucose) to give an initial cell density of $15 \mathrm{~g} \mathrm{~L}^{-1}$ (wet cell weight). Buffer medium was $\mathrm{pH}$-adjusted by adding 
Table 2 Plasmids used in this study

\begin{tabular}{|c|c|c|}
\hline Plasmid & Specific features & Source \\
\hline \multicolumn{3}{|l|}{ Vectors } \\
\hline pGK425 & $\begin{array}{l}\text { Yeast multi-copy type single-gene expression vector containing } P G K 1 \text { promoter, } P G K 1 \\
\text { terminator, } 2 \mu \text { origin, and } L E U 2 \text { marker }\end{array}$ & [37] \\
\hline pAT425 & $\begin{array}{l}\text { Yeast multi-copy type two-gene expression vector containing ADH1 and TDH3 pro- } \\
\text { moters and terminators, } 2 \mu \text { origin, LEU2 marker }\end{array}$ & [39] \\
\hline PATP422 & $\begin{array}{l}\text { Yeast multi-copy type three-gene expression vector containing } A D H 1, T D H 3 \text { and } P G K 1 \\
\text { promoters and terminators, } 2 \mu \text { origin, } A D E 2 \text { marker }\end{array}$ & [39] \\
\hline \multicolumn{3}{|c|}{ Yeast acetolactate synthase (ALS) expressions } \\
\hline pGK425-ILV2 & pGK425, expression of Saccharomyces cerevisiae ALS (ILV2) gene & {$[4]$} \\
\hline pGK425-ILV2c & $\begin{array}{l}\text { pGK425, expression of truncated version of S. cerevisiae ALS lacking the N-terminal } \\
\text { (mitochondrial) signal sequence (ILV2C) gene }\end{array}$ & [38] \\
\hline \multicolumn{3}{|l|}{ ALS expressions } \\
\hline pGK425-ALSAo & pGK425, expression of Aspergillus oryzae ALS (ALS or AO090009000123) gene & This study \\
\hline pGK425-alsSBs & pGK425, expression of Bacillus subtilis ALS (alsS) gene & This study \\
\hline pGK425-alsCg & pGK425, expression of Corynebacterium glutamicum ALS (als or Cg/1271) gene & This study \\
\hline pGK425-ilvBEc & pGK425, expression of Escherichia coli ALS (ilvB) gene & This study \\
\hline pGK425-ilvGEc & pGK425, expression of E. coli ALS (ilvG) gene & This study \\
\hline pGK425-ilvIEC & pGK425, expression of E. coli ALS (i/VI) gene & This study \\
\hline pGK425-AHAS2Gm & pGK425, expression of Glycine max ALS (AHAS2) gene & This study \\
\hline pGK425-AHAS3Gm & pGK425, expression of G. max ALS (AHAS3) gene & This study \\
\hline pGK425-ilvGHe-1 & pGK425, expression of Halomonas elongata ALS (ilvG) gene 1 [HELO_1296] & This study \\
\hline pGK425-ilvGHe-2 & pGK425, expression of H. elongata ALS (ilvG) gene 2 [HELO_2761] & This study \\
\hline pGK425-alsLI & pGK425, expression of Lactococcus lactis ALS (als) gene & This study \\
\hline pGK425-alsLp & pGK425, expression of Lactobacillus plantarum ALS (als) gene & This study \\
\hline pGK425-alsSg-1 & pGK425, expression of Streptomyces griseus ALS (als) gene 1 [SGR_4789] & This study \\
\hline pGK425-alsSg-2 & pGK425, expression of S. griseus ALS (als) gene 2 [SGR_6206] & This study \\
\hline pGK425-alsTf & pGK425, expression of Thermobifida fusca ALS (als) gene [Tfu_061 1] & This study \\
\hline pGK425-ALS1Zm & pGK425, expression of Zea mays ALS (ALS1) gene [100285396] & This study \\
\hline \multicolumn{3}{|c|}{ High-activity ALS expressions (codon optimized) } \\
\hline pGK425-ilvBEcOp & pGK425, expression of E. coli codon-optimized ilvB (ilvBEcOp) gene & This study \\
\hline pGK425-alsLpOp & pGK425, expression of L. plantarum codon-optimized als (alsLpOp) gene & This study \\
\hline pGK425-alsTfOp & pGK425, expression of T. fusca codon-optimized als (alsTfOp) gene & This study \\
\hline pATP422-alsLpOp & pATP422, expression of alsLpOp gene by $P G K 1$ promoter & This study \\
\hline \multicolumn{3}{|c|}{ Acetolactate decarboxylase (ALDC) expressions (codon optimized) } \\
\hline pATP422-alsLpOp-aldcBsOp & $\begin{array}{l}\text { PATP422, expressions of alsLPOp gene by PGK1 promoter and B. subtilis codon-opti- } \\
\text { mized ALDC (aldcBSOp) gene by TDH3 promoter }\end{array}$ & This study \\
\hline pATP422-alsLpOp-aldcEaOp & $\begin{array}{l}\text { PATP422, expressions of alsLPOp gene by PGK1 promoter and Enterobacter aerogenes } \\
\text { codon-optimized ALDC (aldcEaOp) gene by TDH3 promoter }\end{array}$ & This study \\
\hline pATP422-alsLpOp-aldcKpOp & $\begin{array}{l}\text { PATP422, expressions of alsLpOp gene by PGK1 promoter and Klebsiella pneumoniae } \\
\text { codon-optimized ALDC (aldcKpOp) gene by TDH3 promoter }\end{array}$ & This study \\
\hline pATP422-alsLpOp-aldcLIOp & $\begin{array}{l}\text { pATP422, expressions of alsLPOp gene by PGK1 promoter and L. lactis codon-optimized } \\
\text { ALDC (aldcLIOp) gene by TDH3 promoter }\end{array}$ & This study \\
\hline \multicolumn{3}{|c|}{ Yeast butanediol dehydrogenase (BDH) expression } \\
\hline pATP422-alsLpOp-BDH1 & $\begin{array}{l}\text { pATP422, expressions of alsLpOp gene by PGK1 promoter and S. cerevisiae BDH (BDH1) } \\
\text { gene by ADH1 promoter }\end{array}$ & This study \\
\hline pAT425-BDH1 & pAT425, expressions of S. cerevisiae $\mathrm{BDH}(\mathrm{BDH} 1)$ gene by $\mathrm{ADH} 1$ promoter & This study \\
\hline
\end{tabular}

2-(N-morpholino)ethanesulfonic acid (MES) to the SD selection medium. Additional glucose was added to the fermented culture for fed-batch fermentations.

\section{Analysis of extracellular metabolites}

Full details of the analysis of extracellular metabolites are described in Additional file 3: Method S8. 
Table 3 Yeast transformants used in this study

\begin{tabular}{|c|c|c|c|c|c|}
\hline Transformant & Host strain & Plasmid & Gene 1 (ALS) & Gene 2 (ALDC) & Gene 3 (BDH) \\
\hline YIDB001 & YPH499 & pGK425 & - & - & - \\
\hline YIDB002 & YPH499 & pGK425-ILV2 & ILV2 (S. cerevisiae) & - & - \\
\hline YIDB003 & YPH499 & pGK425-ILV2c & ILV2C (S. cerevisiae) & - & - \\
\hline YIDB004 & YPH499 & pGK425-ALSAo & ALSAo (A. oryzae) & - & - \\
\hline YIDB005 & YPH499 & pGK425-alsSBs & alsSBs (B. subtilis) & - & - \\
\hline YIDB006 & YPH499 & pGK425-alsCg & alsCg (C. glutamicum) & - & - \\
\hline YIDB007 & YPH499 & pGK425-ilvBEc & ilvBEC (E. coli) & - & - \\
\hline YIDB008 & YPH499 & pGK425-ilvGEc & ilvGEc (E. coli) & - & - \\
\hline YIDB009 & YPH499 & pGK425-ilvIEc & ilvIEC (E. coli) & - & - \\
\hline YIDB010 & YPH499 & pGK425-AHAS2Gm & AHAS2Gm (G. max) & - & - \\
\hline YIDB011 & YPH499 & pGK425-AHAS3Gm & AHAS3 (G. max) & - & - \\
\hline YIDB012 & YPH499 & pGK425-ilvGHe-1 & ilvGHe-1 (H. elongata) & - & - \\
\hline YIDB013 & YPH499 & pGK425-ilvGHe-2 & ilvGHe-2 (H. elongata) & - & - \\
\hline YIDB014 & YPH499 & pGK425-alsLI & alsLI (L. lactis) & - & - \\
\hline YIDB015 & YPH499 & pGK425-alsLp & alsLp (L.plantarum) & - & - \\
\hline YIDB016 & YPH499 & pGK425-alsSg-1 & alsSg-1 (S. griseus) & - & - \\
\hline YIDB017 & YPH499 & pGK425-alsSg-2 & alssg-2 (S. griseus) & - & - \\
\hline YIDB018 & YPH499 & pGK425-alsTf & $\operatorname{alsTf}(T$. fusca $)$ & - & - \\
\hline YIDB019 & YPH499 & pGK425-ALS1Zm & ALSZm (Z. mays) & - & - \\
\hline YIDB022 & YPH499 & pGK425-ilvBEcOp & ilvBECOp (E. coli, optimized) & - & - \\
\hline YIDB023 & YPH499 & pGK425-alsLpOp & $\begin{array}{l}\text { alsLpOp (L. plantarum, opti- } \\
\text { mized) }\end{array}$ & - & - \\
\hline YIDB024 & YPH499 & pGK425-alsTfOp & alsTfOp (T. fusca, optimized) & - & - \\
\hline YIDB025 & YPH499 & pATP422-alsLpOp & $\begin{array}{l}\text { alsLpOp (L. plantarum, opti- } \\
\text { mized) }\end{array}$ & - & - \\
\hline YIDB030 & YPH499 & pATP422-alsLpOp-aldcBsOp & $\begin{array}{l}\text { alsLpOp (L. plantarum, opti- } \\
\text { mized) }\end{array}$ & aldcBsOp (B. subtilis, optimized) & - \\
\hline YIDB031 & YPH499 & pATP422-alsLpOp-aldcEaOp & $\begin{array}{l}\text { alsLpOp (L. plantarum, opti- } \\
\text { mized) }\end{array}$ & $\begin{array}{l}\text { aldcEaOp (E. aerogenes, opti- } \\
\text { mized) }\end{array}$ & - \\
\hline YIDB032 & YPH499 & pATP422-alsLpOp-aldcKpOp & $\begin{array}{l}\text { alsLpOp (L. plantarum, opti- } \\
\text { mized) }\end{array}$ & $\begin{array}{l}\text { aldcKpOp (K.pneumoniae, } \\
\text { optimized) }\end{array}$ & - \\
\hline YIDB033 & YPH499 & pATP422-alsLpOp-aldcLIOp & $\begin{array}{l}\text { alsLpOp (L. plantarum, opti- } \\
\text { mized) }\end{array}$ & aldcLIOp (L. lactis, optimized) & - \\
\hline YIDB034 & YPH499 & pATP422-alsLpOp-BDH1 & $\begin{array}{l}\text { alsLpOp (L. plantarum, opti- } \\
\text { mized) }\end{array}$ & - & BDH1 (S. cerevisiae) \\
\hline YHI010 & YSM046 & pGK425-alsLpOp & $\begin{array}{l}\text { alsLpOp (L. plantarum, opti- } \\
\text { mized) }\end{array}$ & - & - \\
\hline YHI011 & YSM046 & pATP422-alsLpOp-aldcLIOp & $\begin{array}{l}\text { alsLpOp (L. plantarum, opti- } \\
\text { mized) }\end{array}$ & aldcLIOp (L. lactis, optimized) & - \\
\hline YHI027 & YPH499 & $\begin{array}{l}\text { pATP422-alsLpOp-aldcLIOp/ } \\
\text { pAT425-BDH1 }\end{array}$ & $\begin{array}{l}\text { alsLpOp (L. plantarum, opti- } \\
\text { mized) }\end{array}$ & aldcLIOp (L. lactis, optimized) & BDH1 (S. cerevisiae) \\
\hline YHI030 & YSM046 & $\begin{array}{l}\text { pATP422-alsLpOp-aldcLIOp/ } \\
\text { pAT425-BDH1 }\end{array}$ & $\begin{array}{l}\text { alsLpOp (L. plantarum, opti- } \\
\text { mized) }\end{array}$ & aldcLIOp (L. lactis, optimized) & BDH1 (S. cerevisiae) \\
\hline YSHB001 & YSM021 & $\begin{array}{l}\text { pATP422-alsLpOp-aldcLIOp/ } \\
\text { pAT425-BDH1 }\end{array}$ & $\begin{array}{l}\text { alsLpOp (L. plantarum, opti- } \\
\text { mized) }\end{array}$ & aldcLIOp (L. lactis, optimized) & BDH1 (S. cerevisiae) \\
\hline
\end{tabular}

The concentrations of 2,3-BDO, glucose, ethanol, glycerol, acetoin, pyruvate, acetate, lactate and succinate in the culture medium were determined using a high-performance liquid chromatography (HPLC) system (with UV/Vis and refractive index detectors) (Shimadzu, Kyoto, Japan) equipped with an Aminex 
HPX-87H column $(300 \times 7.8 \mathrm{~mm})($ Bio-Rad, Hercules, CA, USA).

\section{LC-MS/MS analysis of intermediate metabolites}

Full details of the LC-MS/MS analysis of the intermediate metabolites are described in Additional file 3: Method S9. Metabolite analysis was performed using a previously described method [35].

\section{Results}

\section{Selection of acetolactate synthase (ALS) for 2,3-BDO} biosynthesis

ALS is the first-step enzyme in valine biosynthesis, catalyzes the conversion of pyruvate to 2 -acetolactate, and is important for 2,3-BDO biosynthesis (Fig. 1a, b) [4, 36]. To tug the carbon flux from pyruvate and enhance 2,3BDO biosynthesis in $S$. cerevisiae, we isolated the genes encoding ALS enzymes from various species. Sixteen ALS genes from 11 species other than S. cerevisiae (12 genes were from eight prokaryotes and 4 genes were from three eukaryotes) were cloned into the pGK425 yeast expression vector [37] (Table 2) and expressed under the PGK1 promoter in YPH499 (wild-type) yeast strain (Table 3 ). The relative ALS activities of crude cell extracts were measured after $48 \mathrm{~h}$ of cultivation (Fig. 2). ILV2 (encoding the endogenous $S$. cerevisiae ALS [4]) and $I L V 2 c$ (a truncated version of the $I L V 2$ gene lacking the mitochondrial signal sequence to localize Ilv2 in cytosol [38]) genes (Fig. 1a, b) were used as positive controls to assess the capabilities of the ALS enzymes. Most of the constructed strains showed higher ALS activities than the control strain (harboring the mock control vector) that inherently contains the ILV2 gene in the genome (Fig. 2). Eight strains exhibited higher ALS activities than the strain expressing the truncated (cytosolic) $I L V 2 c$ gene, and five strains displayed higher ALS activities than the strain overexpressing the intact (mitochondrial) ILV2 gene. The relative measured ALS activities were used to identify the top three genes as alsLp (from Lactobacillus plantarum; 27.8-fold), ilvBEc (from Escherichia coli; 5.5-fold) and alsTf (from Thermobifida fusca; 2.8-fold). Notably, the alsLp gene encoded an enzyme with much higher ALS activity than any other ALS tested (Fig. 2).

The top three ALS genes were introduced into yeast cells and 2,3-BDO fermentations were performed in test tubes (Fig. 3a). Strains harboring the mock vector and the $I L V 2 c$ expression plasmid were, respectively, used as negative and positive controls. The alsLp, ilvBEc and alsTf genes were codon-optimized (alsLpOp, ilvBEcOp and alsTfOp), subcloned into the same pGK425 expression vector (Table 2), and introduced into YPH499 (Table 3). The obtained strains were cultured in test tubes with $3 \mathrm{~mL}$ of SD medium (containing $20 \mathrm{~g} \mathrm{~L}^{-1}$ glucose) under semi-aerobic conditions (Fig. 3a). The expression of $I L V 2 c$ in YPH499 resulted in a four-time higher 2,3-BDO titer (141 $\mathrm{mg} \mathrm{L}^{-1}$ ) compared to the negative control strain (35 $\mathrm{mg} \mathrm{L}^{-1}$ ), and expression of the top three ALS genes

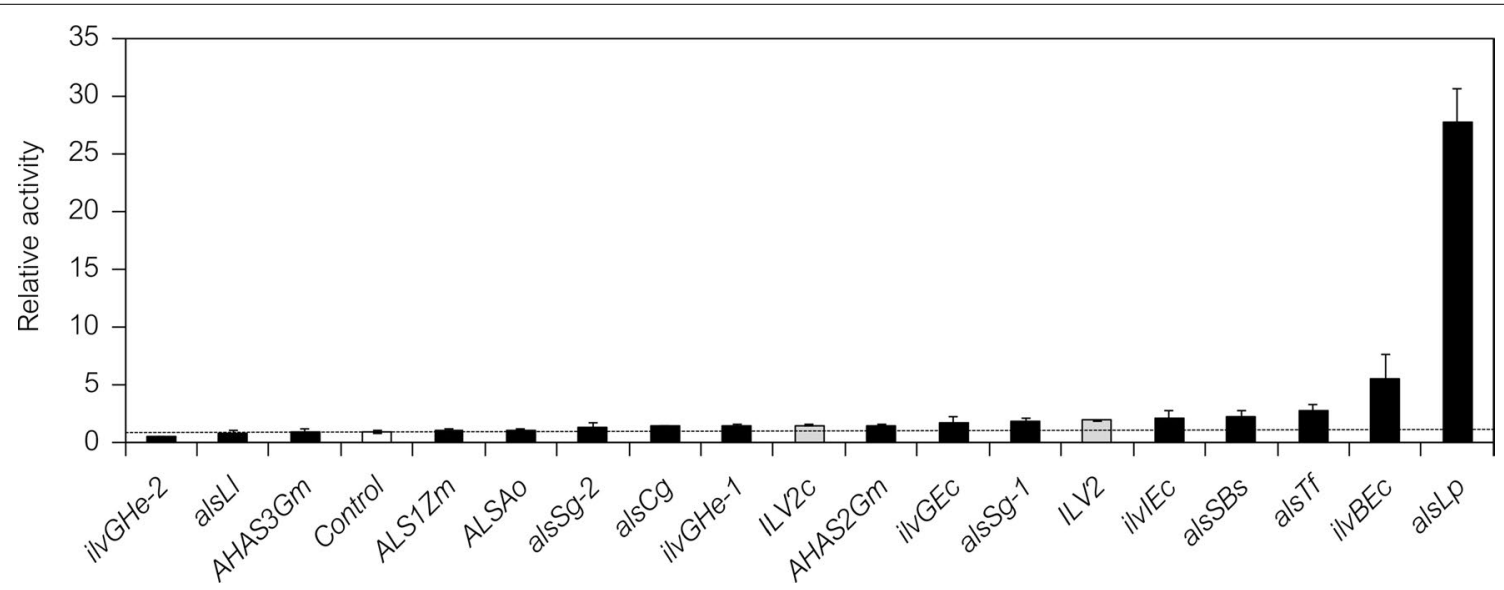

Fig. 2 Relative enzymatic activities of acetolactate synthase (ALS) in crude yeast cell extracts. Various ALS (ilv and als) genes were expressed in S. cerevisiae YPH499 strain (YIDB001-019). Crude protein extracts were prepared from cells grown in $5 \mathrm{~mL}$ SD selection medium for $48 \mathrm{~h}$ and used to measure relative ALS enzyme activities (see Additional file 3: Method S6). The white bar shows the relative ALS activity of the control strain harboring a mock control vector (pGK425; YIDB001) and was used for normalization. The gray bars show the relative ALS activities of yeast strains expressing the ILV2 gene (encoding the endogenous S. cerevisiae ALS; YIDB002) and the ILV2c gene (a truncated version of the ILV2 gene lacking the mitochondrial signal sequence to localize IIv2p in the cytosol; YIDB003) as positive controls. The black bars show the relative ALS activities of yeast strains expressing various ALS genes (YIDB004-019). Ao, Aspergillus oryzae; Bs, Bacillus subtilis; Cg, Corynebacterium glutamicum; Ec, Escherichia coli; Gm, Glycine max; He, Halomonas elongata; LI, Lactococcus lactis; Lp, Lactobacillus plantarum; Sg, Streptomyces griseus; Tf, Thermobifida fusca; Zm, Zea mays. Data are presented as the mean \pm standard deviation of three independent transformants ( $n=3$ each) 

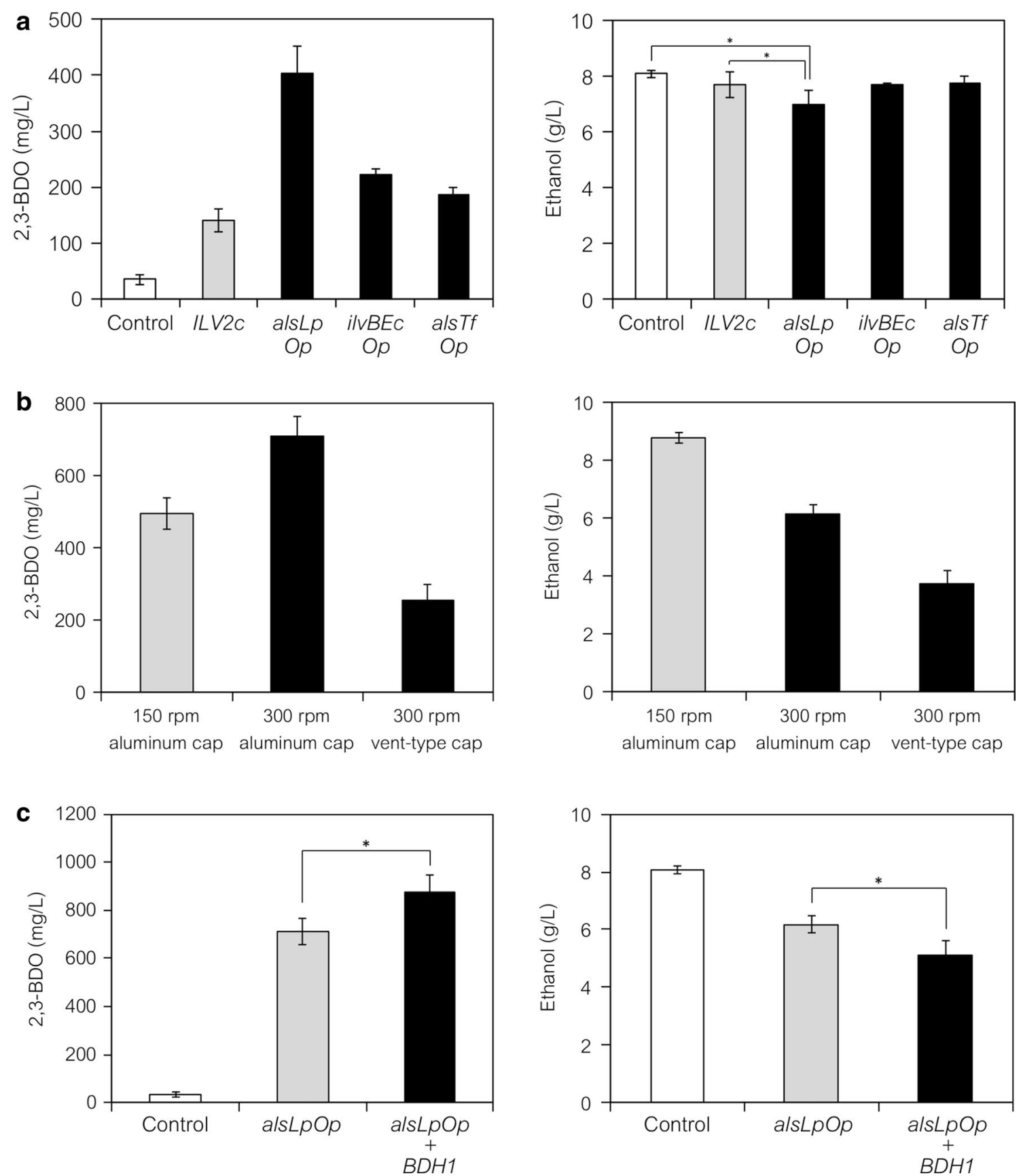

Fig. 3 Investigation of genotype and aeration conditions for 2,3-BDO production by the YPH499 wild-type strain. Ec, Escherichia coli; Lp, Lactobacillus plantarum; Tf, Thermobifida fusca. Op, codon-optimized. Fermentations were performed in test tubes containing $3 \mathrm{~mL}$ of SD selection medium (20 $\mathrm{g} \mathrm{L}^{-1}$ glucose) under the indicated aeration conditions. The concentrations of 2,3-BDO and ethanol in the media were determined at $48 \mathrm{~h}$ after the start of fermentation. a 2,3-BDO production by YPH499 strains expressing high-activity ALSs (black bars; YIDB022-025) under semi-aerobic conditions (150 rpm, aluminum cap). A truncated version of the ILV2 gene (ILV2C), which is expressed in the cytosol, was used as a comparative yeast ALS (gray bars). YPH499 harboring the mock vector was used as the negative control (white bars). b Effect of aeration on 2,3-BDO production by YPH499 strain expressing high-activity ALS (alsLpOp gene; YIDB025). The agitation speed (150 rpm) was increased to $300 \mathrm{rpm}$ and the cover cap on the test tube was changed from an aluminum cap to a vent-type cap to increase the aeration. The gray bars indicate the baseline (former) conditions (150 rpm, aluminum cap) and the black bars indicate the altered conditions (300 rpm, aluminum or vent-type cap). c 2,3-BDO production by YPH499 strains co-expressing high-activity ALS (alsLpOp gene) and yeast endogenous BDH (BDH1 gene) (black bars; YIDB034) under aerobic conditions (300 rpm, aluminum cap). YPH499 expressing only the ALS (alsLpOp) gene was used as the comparative control (gray bars). The YPH499 wild-type strain was used as the negative control (white bars). Data are, respectively, presented as the mean \pm standard deviation of three independent transformants (for $\mathbf{a}$ and $\mathbf{c}$ ) and of three separate cultivations (for $\mathbf{b})(n=3$ each). Statistical significance was assessed by the $t$ test $\left({ }^{*} p<0.05\right)$ 
further increased the titer of 2,3-BDO. The increased levels of 2,3-BDO correlated with the strength of the relative ALS activity (Fig. 2). YPH499 strain expressing the alsLpOp gene yielded $403 \mathrm{mg} \mathrm{L}^{-1} 2,3-\mathrm{BDO}$, while those expressing the $i l v B E c O p$ or alsTfOp genes produced 223 and $188 \mathrm{mg} \mathrm{L}^{-1}$ 2,3-BDO (Fig. 3a), respectively. The strain expressing als $L p O p$ resulted in a slight decrease in ethanol concentration $\left(7.0 \mathrm{~g} \mathrm{~L}^{-1}\right)$ compared to the mock control strain $\left(8.1 \mathrm{~g} \mathrm{~L}^{-1}\right)$ and the strain expressing $I L V 2 c$ $\left(7.7 \mathrm{~g} \mathrm{~L}^{-1}\right)(p<0.05$; Fig. 3a).

\section{Demonstration of the tugging of pyruvate flux by simple tuning using a high-activity ALS-expressing wild-type strain}

We increased the titer of 2,3-BDO and reduced ethanol subgeneration by further tuning the wild-type yeast strain expressing a high-activity ALS (alsLpOp) by introducing the expression of additional genes (ALDC genes and $B D H 1$ ) and altering the aeration conditions (Additional file 1: Fig. S2, Fig. 3b, c). Co-expression of the alsLpOp and ALDC (codon-optimized) genes from several bacteria using the pATP422 multiple gene expression vector [39] (Table 2) in YPH499 (Table 3; YIDB030-033) did not result in an increase in 2,3-BDO compared to the strain expressing only the alsLpOp gene (Additional file 1: Fig. S2). This decrease in productivity might be attributed to the reduced consumption of NADH in 2,3-BDO biosynthesis via the ALDC reaction (Fig. 1c). Briefly, the ALDC pathway does not use NADH to convert 2-acetolactate to acetoin (Fig. 1c), while the alternative diacetyl pathway uses NADH through the reaction of diacetyl reductase (encoded by BDH1 in S. cerevisiae) (Fig. 1b). Consequently, the overexpression of ALDC might decrease carbon flux toward 2,3-BDO to consume excess NADH during ethanol biosynthesis. Indeed, the ALDC-expressing strains produced higher amounts of ethanol than the non-expressing strain (data not shown).

Culture conditions (aeration) were investigated by changing the agitation speed (150-300 rpm) and the cover cap on the test tubes (aluminum cap to a vent-type cap, SILICOSEN ${ }^{\circledR}$ ) using the YPH499 strain expressing the ALS (alsLpOp) gene (Fig. 3b). Under the same conditions as used for the previous cultures (aluminum cap, $150 \mathrm{rpm}$ ), the strain produced $494 \mathrm{mg} \mathrm{L}^{-1} 2,3-\mathrm{BDO}$ and $8.8 \mathrm{~g} \mathrm{~L}^{-1}$ ethanol. The titers of YPH499 expressing the ALS $(a l s L p O p)$ gene slightly differed from those shown in Fig. 3a, possibly due to differences between the vector backbones (pGK425 and pATP422 in Fig. 3a, $\mathrm{b}$, respectively). As aeration increased (aluminum cap and vent-type cap, $300 \mathrm{rpm})$, significant decreases in ethanol production were observed (6.2 and $\left.3.7 \mathrm{~g} \mathrm{~L}^{-1}\right)$ (Fig. 3b). A moderate increase in aeration (aluminum cap, $300 \mathrm{rpm}$ ) resulted in a higher $2,3-\mathrm{BDO}$ production titer $\left(711 \mathrm{mg} \mathrm{L}^{-1}\right)$, whereas a large increase in aeration (vent-type cap, $300 \mathrm{rpm}$ ) reduced the 2,3-BDO titer (256 mg L ${ }^{-1}$ ) (Fig. 3b). It is possible that excessive aeration (vent-type cap, $300 \mathrm{rpm}$ ) may have resulted in the redirection of pyruvate flux towards the TCA cycle, faster respiration, and/or the evaporation of ethanol. Regardless, YPH499 expressing the ALS (alsLpOp) gene under high aeration conditions produced ethanol titers consistent with previous reports [20,21]. In contrast, conditions of reduced aeration (aluminum cap, $300 \mathrm{rpm}$ ) could have reduced the spontaneous decarboxylation required for converting 2-acetolactate to diacetyl because this reaction requires moderate concentrations of oxygen [12].

$B D H 1$, which encodes endogenous yeast $\mathrm{BDH}$, was overexpressed along with alsLpOp using the pATP422 multiple gene expression vector (Table 2) in YPH499 (Table 3; YIDB034), resulting in the 2,3-BDO titer increasing up to $874 \mathrm{mg} \mathrm{L}^{-1}(p<0.05$; Fig. 3c). The titer of ethanol was reduced to $5.1 \mathrm{~g} \mathrm{~L}^{-1}(p<0.05$; Fig. 3c) because the carbon flux to 2,3-BDO biosynthesis was further enhanced by the additional expression of Bdh1 enzyme (Fig. 1b). These results demonstrated the validity of the pyruvate carbon flux strategy for 2,3-BDO production in the wild-type strain using high-activity ALS (the als $L p O p$ gene). However, this engineered strain (expressing the als $L p O p$ and $B D H 1$ genes) still exhibited a high titer of ethanol. Consequently, the disruption of ethanol biosynthesis is a strategy for tugging pyruvate carbon flux and further improving 2,3-BDO production.

\section{Construction of a pyruvate decarboxylase-deficient (PDC $\Delta$ ) strain (YSM021 strain)}

Full details of the results for constructing the PDC $\Delta$ (YSM021) strain are described in Additional file 3: Result S1. Briefly, we disrupted ethanol biosynthesis by following the strategy used to construct the previously reported pyruvate decarboxylase-deficient $\mathrm{Pdc}^{-}$strain (deletion of the coding DNA sequence (CDS) regions of the PDC1, PDC5 and PDC6 genes, and introduction of the $M T H 1-\triangle T$ allele) [40]. We constructed the pyruvate decarboxylase-deficient PDC $\Delta$ strain YSM021 (Table 1) from YPH499, and confirmed quadruple gene deletion (MTH1- $\Delta T p d c 1 \Delta p d c 5 \Delta p d c 6 \Delta$ ) by genome re-sequencing (Fig. $4 \mathrm{a}-\mathrm{d}$ ). The genome sequence of YSM021 strain further revealed the occurrence of a nonsynonymous substitution (L165F) in the MTH1- $\triangle T$ gene due to a single nucleotide polymorphism (SNP) located at position 468 (from A to C) (Fig. 4d, Table 1). Although the glucose consumption of YSM021 was much slower than that of YPH499, no ethanol, glycerol, or acetate production was detected in YSM021 cultures after $120 \mathrm{~h}$ of cultivation (Additional file 1: Fig. S3) but pyruvate accumulated with time (Additional file 1: Fig. S3). 

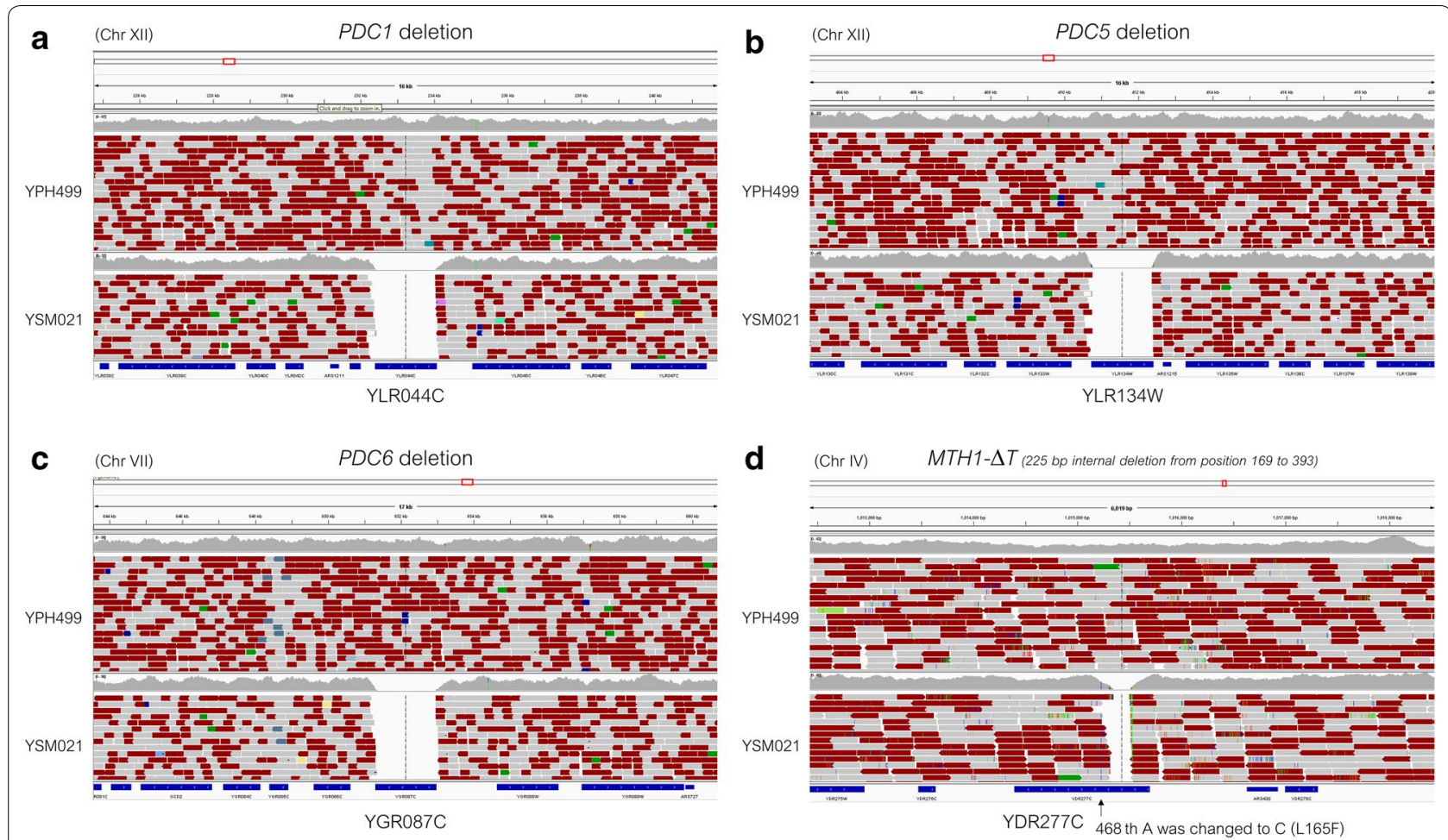

Fig. 4 Deletion of genome regions in the PDC $\triangle$ (YSM021) strain. Deletion of the coding DNA sequence (CDS) regions of PDC1 (a), PDC5 (b), PDC6 (c) and the internal deletion of MTH1 (MTHT- $\triangle T$ ) (d) was confirmed by genome sequencing (pair-end sequencing using Illumina MiSeq and Miseq V2 500 cycle kits). The data were processed and displayed using Integrative Genomic Viewer version 2.3.81

\section{Laboratory evolution of the PDC $\Delta$ strain and genome re-sequencing}

Full details of the laboratory evolution of the PDC $\Delta$ (YSM021) strain and genome re-sequencing are described in Additional file 3: Result S2. Briefly, laboratory evolution of the PDCA (YSM021) strain using a series of five independent cultures allowed for faster growth of culture series 1 (Additional file 1: Fig. S4). Three colonies isolated from the cells collected at days 44 and 122 (Evo44 and Evo122) (Table 1) showed improved cell growth phenotypes (Fig. 5).

Genome re-sequencing revealed several nonsynonymous mutations, including an $\mathrm{A}$ to $\mathrm{T}$ mutation at position 1547 (D516V) in the YAK1 gene (YJL141C) and a $\mathrm{G}$ to A mutation at position 605 (G202D) in the MCT1 gene (YOR221C) (Table 4). MCT1 is predicted to encode a malonyl-CoA:ACP transferase responsible for lipid biosynthesis [41]. YAK1 encodes a serine-threonine protein kinase that inhibits growth in response to glucose availability in a glucose-sensing system [42, 43], suggesting that the mutation in $Y A K 1$ is likely responsible for the observed improved cell growth rate. Further genetic characterization of these mutations (including L165F in the $M T H 1-\triangle T$ gene) is in progress and will be reported elsewhere in the future.

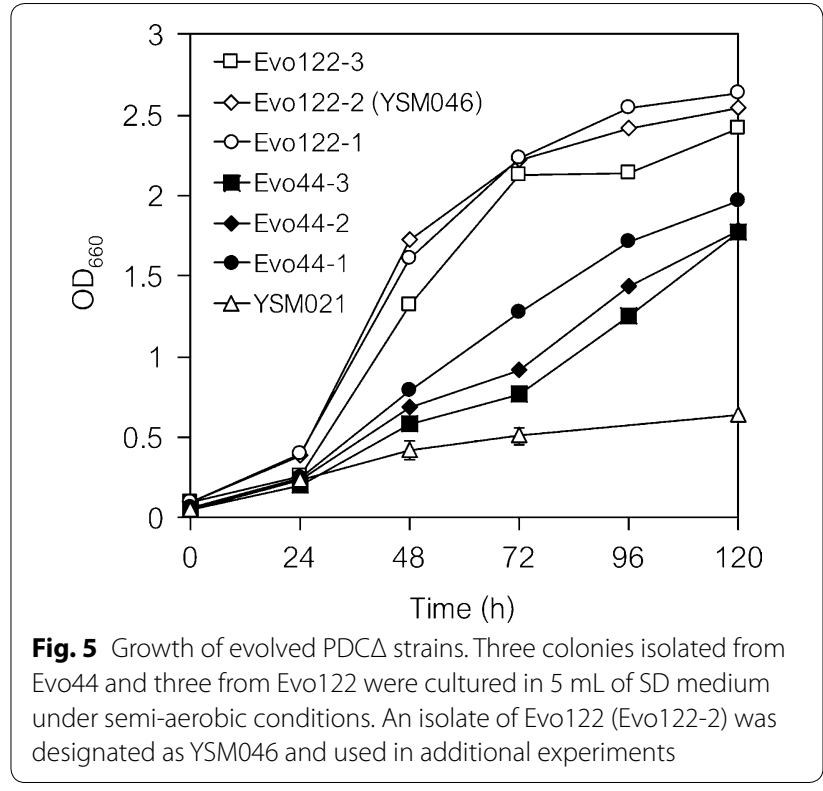

An isolate of Evo122 (Evo122-2) was designated as YSM046 (Table 1) and used for 2,3-BDO production. A comparison of culture profiles indicated that the cell growth rate of YSM046 strain was significantly improved 
Table 4 Mutations commonly observed in isolates of the evolved strain

\begin{tabular}{|c|c|c|c|c|c|c|c|}
\hline Chromosome & Coordinate & ORFs & Position (bp) & Mutation & Type & Evo44 & Evo122 \\
\hline Chr 2 & 27308 & YBL101C (ECM21) & 991 & $\mathrm{~T} \rightarrow-$ (deletion) & Frame shift & nd & + \\
\hline Chr 3 & 253645 & YCR079W (PTC6) & 804 & $C \rightarrow T$ & Synonymous & nd & + \\
\hline Chr 5 & 288490 & $\mathrm{tS}(\mathrm{UGA}) \mathrm{E}(\mathrm{SUP} 19)$ & 35 & $G \rightarrow C$ & - & nd & + \\
\hline Chr 10 & 148840 & YJL141C (YAK1) & 1547 & $\mathrm{~A} \rightarrow \mathrm{T}(\mathrm{D} 516 \mathrm{~V})$ & Nonsynonymous & + & + \\
\hline Chr 15 & 756954 & YOR221C (MCT1) & 605 & $\mathrm{G} \rightarrow \mathrm{A}(\mathrm{G} 202 \mathrm{D})$ & Nonsynonymous & + & + \\
\hline
\end{tabular}

nd not detected

compared to YSM021, and ethanol and glycerol were not produced (Additional file 1: Fig. S3).

Metabolic state of the evolved PDC $\Delta$ strain (YSM046 strain) The state of central carbon metabolism in the evolved strain was investigated by metabolic profiling analysis. The wild-type strain (YPH499) and the evolved strain (YSM046, PDC $\Delta+$ evolved) (Table 1) were cultivated in shake flasks with $100 \mathrm{~mL}$ SD medium under aerobic conditions (Fig. 6). Glucose was slowly consumed by the YSM046 strain and no ethanol and little glycerol were produced (Fig. 6), consistent with the small-scale cultivation data (Additional file 1: Fig. S3). The specific growth rates of YPH499 and the evolved strain YSM046 were $0.30 \pm 0.003$ and $0.091 \pm 0.002 \mathrm{~h}^{-1}$, respectively. Intracellular metabolites were extracted from cells collected at mid-log phase $\left(\mathrm{OD}_{660}=1.0\right.$; see "Methods" for the detailed procedure) and metabolite concentrations were determined by ion-pairing LC-MS/MS analysis (Fig. 7).

Comparison of the pool sizes of glycolytic intermediates and cofactors indicated that two substrates for the PDC (pyruvate decarboxylase) and ADH (alcohol dehydrogenase) reactions, pyruvate and $\mathrm{NADH}$, significantly accumulated (3.9- and 3.2-fold, respectively) in the evolved PDC $\Delta$ strain YSM046 cells (Fig. 7). The reduced levels of energy charge (decreased ATP and increased ADP) and fructose 1,6-bisphosphate (FBP: only 15.3\% that of YPH499) in YSM046 cells suggested that the low ATP level should have affected the activity of phosphofructokinase (fructose 6-phosphate $(\mathrm{F} 6 \mathrm{P})+\mathrm{ATP} \rightarrow \mathrm{FBP}+\mathrm{ADP})$, resulting in slower glycolysis in the YSM046 strain. However, the level of pyruvate accumulation was suitable for demonstrating our strategy and thus we further exploited the YSM046 strain to validate the utility of tugging the pyruvate flux for 2,3-BDO production.

Construction of 2,3-BDO-producing evolved PDC $\Delta$ strains harboring high-activity ALS and downstream aldcLIOp and $B D H 1$ genes (YHI030 strain)

Saccharomyces cerevisiae strains producing 2,3-BDO were constructed by introducing the high-activity ALS $(a l s L p O p)$ gene and/or the downstream (ALDC and $\mathrm{BDH}$; aldcLlOp and BDH1) genes for 2,3-BDO biosynthesis into the YSM046-evolved PDCA strain (YHI010, YHI011 and YHI030; Table 3) and the YPH499 wild-type strain (YHI027; Table 3). The strains were cultured in $5 \mathrm{~mL}$ of SD selection medium under semi-aerobic conditions. The concentrations of 2,3-BDO and other compounds $96 \mathrm{~h}$ after the start of fermentation are shown in Fig. 8.

Both glucose consumption and 2,3-BDO titer were increased by sequential introduction of the alsLpOp, aldcLlOp and BDH1 genes into the YSM046 strains (Fig. 8). The 2,3-BDO titer of YHI030 strain (YSM046 strain expressing alsLpOp, aldcLlOp and BDH1) was $6.6 \pm 2.2 \mathrm{~g} \mathrm{~L}^{-1}$ (0.41 $\mathrm{g} \mathrm{g}^{-1}$ glucose consumed), comparable to the highest value reported for $S$. cerevisiae $[12,26])$. We observed no over-production of 2,3-BDO by YHIO27 strain expressing the same (alsLpOp, aldcLlOp and BDH1) genes present in wild-type YPH499 $\left(0.37 \pm 0.05 \mathrm{~g} \mathrm{~L}^{-1} ; 0.02 \mathrm{~g} \mathrm{~g}^{-1}\right.$ glucose consumed). No ethanol was detected in the culture media of the YSM046derived strains (YHI030, YHI011 and YHI010) whereas YHI027 strain produced $3.7 \pm 0.3 \mathrm{~g} \mathrm{~L}^{-1}$ ethanol as the major product. YHI030 showed slightly higher (1.7-fold) glycerol production than YHI027 (Fig. 8), probably due to an excess of NADH resulting from the loss of ethanol biosynthesis. The higher growth rate of the evolved PDC $\Delta$ strain (YSM046) compared to the non-evolved PDCA strain (YSM021) was confirmed, even when YSM046 expressed the alsLpOp, aldcLlOp and BDH1 genes (Table 3, Additional file 1: Fig. S5). These results indicate that the YSM046-evolved PDC $\Delta$ strain is useful as a host strain for tugging pyruvate carbon flux and increasing 2,3-BDO production, although its growth rate requires improvement prior to industrial application.

\section{2,3-BDO production by fermentation using YHI030 strain}

2,3-BDO was further produced by fermentation using the YHI030 strain. Small fermentation bottles containing SD selection medium and several high concentrations of glucose $\left(25,50\right.$ and $\left.100 \mathrm{~g} \mathrm{~L}^{-1}\right)$ as the sole carbon source were used to generate oxygen-limited (anaerobic) conditions. 


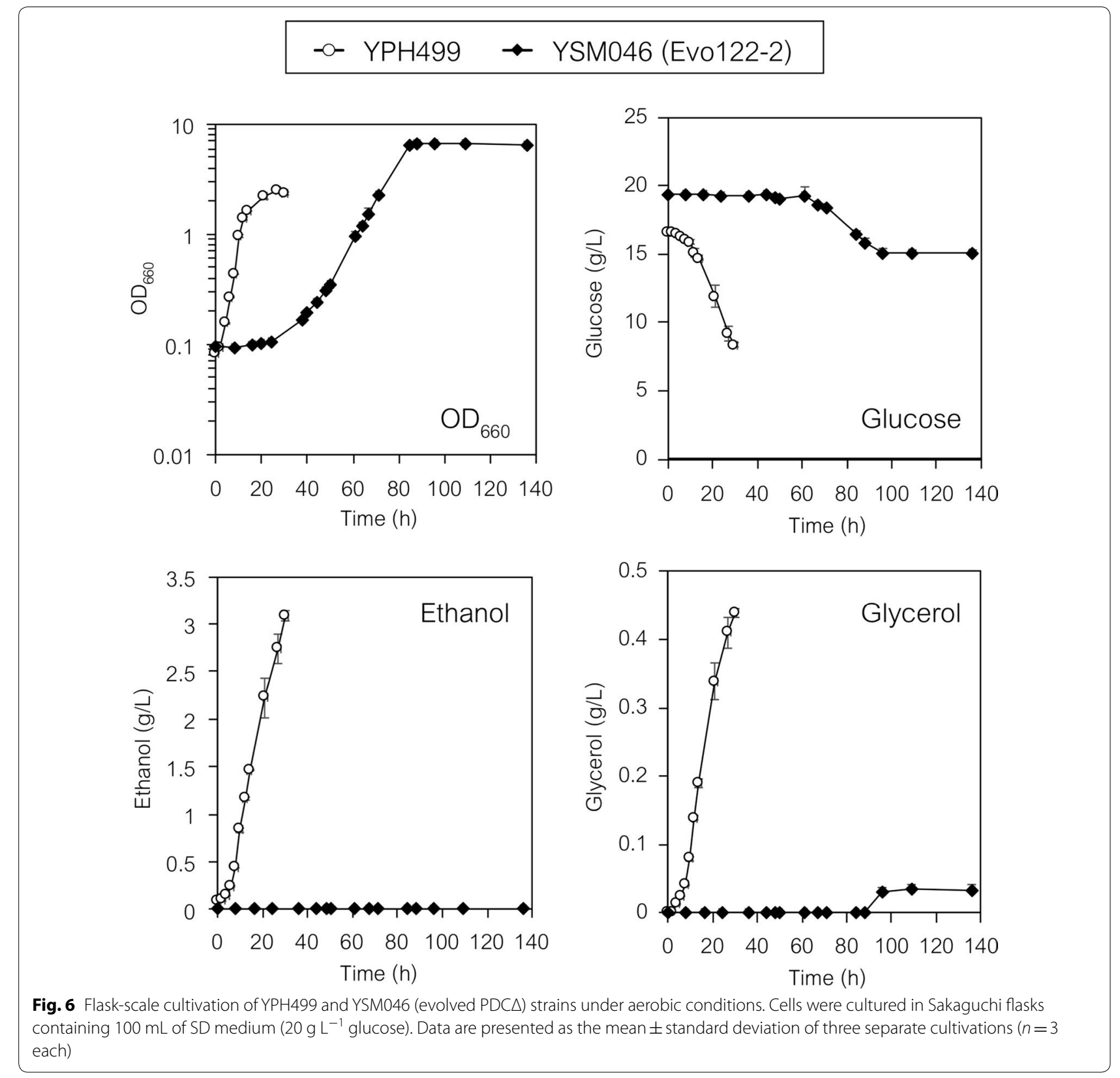

The cells almost completely consumed 25 and $50 \mathrm{~g} \mathrm{~L}^{-1}$ glucose after 24 and $48 \mathrm{~h}$ of fermentation, respectively (Fig. 9a, b). After 48 and $72 \mathrm{~h}$ of fermentation, the 2,3-BDO titer of YHI030 strain was $9.1 \pm 0.4 \mathrm{~g} \mathrm{~L}^{-1}\left(0.37 \mathrm{~g} \mathrm{~g}^{-1}\right.$ glucose consumed) and $17.4 \pm 0.3 \mathrm{~g} \mathrm{~L}^{-1}\left(0.35 \mathrm{~g} \mathrm{~g}^{-1}\right.$ glucose consumed), respectively, from 25 and $50 \mathrm{~g} \mathrm{~L}^{-1}$ glucose, and the glycerol titer was, respectively, $7.4 \pm 0.2 \mathrm{~g} \mathrm{~L}^{-1}\left(0.30 \mathrm{~g} \mathrm{~g}^{-1}\right.$ glucose consumed) and $15.3 \pm 0.6 \mathrm{~g} \mathrm{~L}^{-1}\left(0.31 \mathrm{~g} \mathrm{~g}^{-1}\right.$ glucose consumed). Although the cells produced $22.1 \pm 1.1$ $\mathrm{g} \mathrm{L}^{-1} 2,3-\mathrm{BDO}$ (0.38 $\mathrm{g} \mathrm{g}^{-1}$ glucose consumed) and
$19.7 \pm 1.6 \mathrm{~g} \mathrm{~L}^{-1}$ glycerol ( $0.34 \mathrm{~g} \mathrm{~g}^{-1}$ glucose consumed) from $100 \mathrm{~g} \mathrm{~L}^{-1}$ glucose after $96 \mathrm{~h}$ of fermentation, the glucose consumption rate decreased after $48 \mathrm{~h}$ and the $100 \mathrm{~g} \mathrm{~L}^{-1}$ of glucose was not completely consumed (Fig. 9c). For all concentrations of glucose, the yields of 2,3-BDO and glycerol were, respectively, 0.35-0.38 and $0.30-0.34 \mathrm{~g} \mathrm{~g}^{-1}$ glucose consumed, whereas very low levels of the other metabolites measured (ethanol, acetate, lactate, succinate and pyruvate) were detected in the fermentation media. The relatively high levels of glycerol generation were probably caused by the excess 


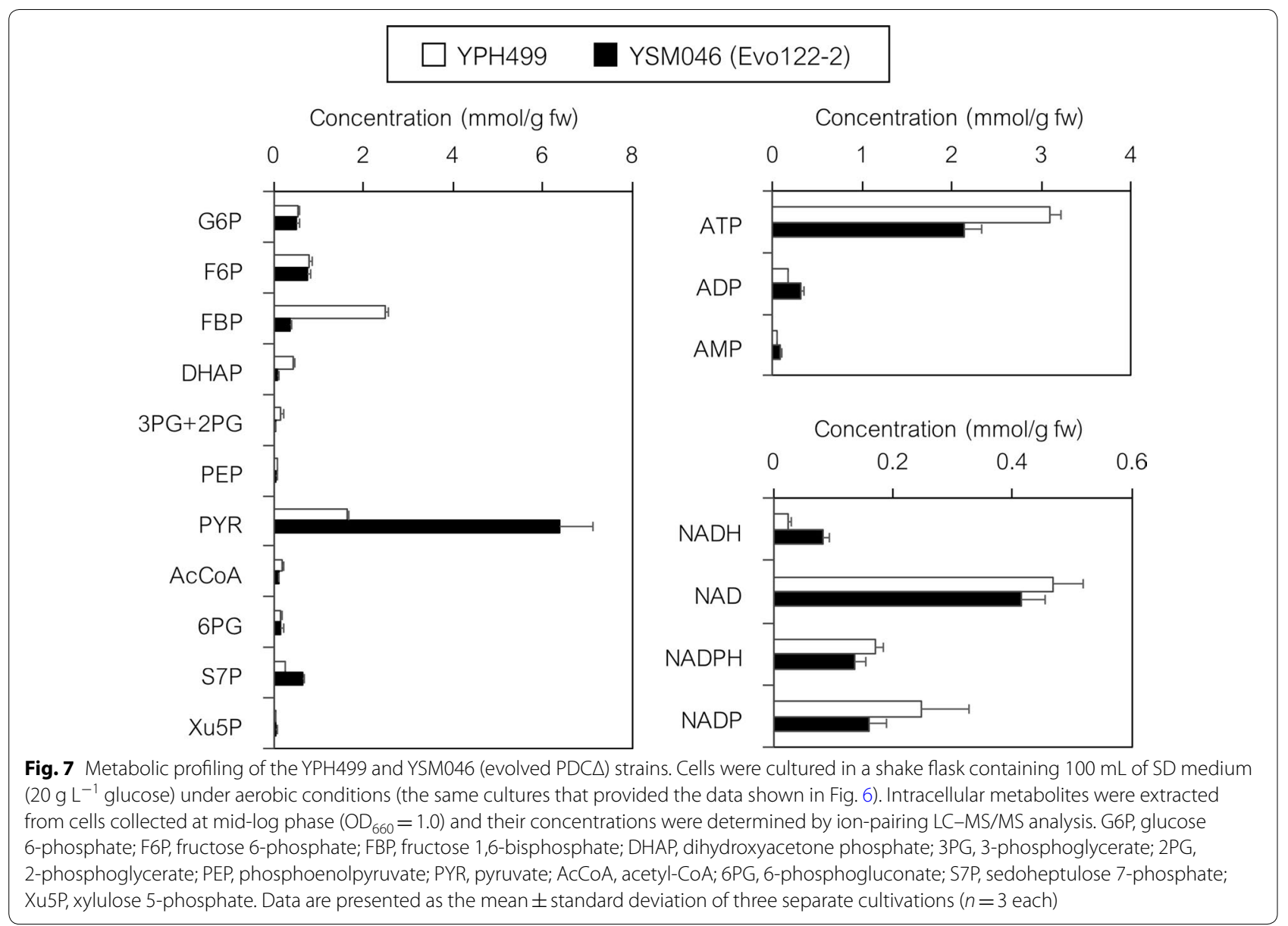

of NADH arising from deficient ethanol biosynthesis (similar to the results shown in Fig. 8).

\section{Investigation of fermentation conditions for 2,3-BDO production by $\mathrm{YHIO} 030$ strain}

Since not all the $100 \mathrm{~g} \mathrm{~L}^{-1}$ glucose was consumed during fermentation (Fig. 9c), we investigated the effects of adding glucose in a step-by-step manner (Additional file 1: Fig. S6). During anaerobic fermentation, 50 or $25 \mathrm{~g} \mathrm{~L}^{-1}$ glucose was added to the culture in incremental steps (Additional file 1: Fig. S6A and B). In both cases, the cells showed decreased glucose consumption after the addition of a total of $50 \mathrm{~g} \mathrm{~L}^{-1}$ glucose. The 2,3-BDO titer remained static at around $20 \mathrm{~g} \mathrm{~L}^{-1}$.

Subsequently, we tested the effect of aerobic fermentation in SD selection medium (50 and $100 \mathrm{~g} \mathrm{~L}^{-1}$ glucose) using Erlenmeyer flasks and different agitation speeds (100 and $200 \mathrm{rpm}$ ) (Additional file 1: Fig. S7). At 100rpm agitation, YHI030 strain produced approximately $20 \mathrm{~g} \mathrm{~L}^{-1} 2,3-\mathrm{BDO}$ in medium containing initially either 50 or $100 \mathrm{~g} \mathrm{~L}^{-1}$ glucose (Additional file 1: Fig. S7A and $\mathrm{B}$ ); in medium containing initially $100 \mathrm{~g} \mathrm{~L}^{-1}$ glucose, the cells consumed approximately $40 \mathrm{~g} \mathrm{~L}^{-1}$ glucose (Additional file 1: Fig. S7B). The production of glycerol was significantly reduced when fermentation was conducted in medium containing initially either 50 or $100 \mathrm{~g} \mathrm{~L}^{-1}$ glucose and agitated at $100 \mathrm{rpm}$ (4.7 and $7.2 \mathrm{~g} \mathrm{~L}^{-1}$ glycerol, respectively) (Additional file 1: Fig. S7A and B).

The fermentation of either 50 or $100 \mathrm{~g} \mathrm{~L}^{-1}$ glucose under more aerobic conditions $(200 \mathrm{rpm})$ resulted in lower 2,3-BDO production $\left(\sim 14 \mathrm{~g} \mathrm{~L}^{-1}\right)$ and decreased glucose consumption $\left(\sim 30 \mathrm{~g} \mathrm{~L}^{-1}\right)$ (Additional file 1: Fig. S7C and D), indicating that conditions approximating an oxygen-limited aerobic state are suitable for 2,3-BDO production by YHI030 strain. Furthermore, all cultures showed increased cell densities $(\mathrm{OD}=20-25)$ and a significant decrease in $\mathrm{pH}(2-3)$ after $24 \mathrm{~h}$ of fermentation (Additional file 1: Fig. S7C and D). Fermentation at $300 \mathrm{rpm}$ in medium containing 50 or $100 \mathrm{~g} \mathrm{~L}^{-1}$ glucose resulted in 2,3-BDO production profiles similar to those at obtained at $200 \mathrm{rpm}$ (data not shown).

We investigated the effect of severely decreased $\mathrm{pH}$ on the production of 2,3-BDO by adding $200 \mathrm{mM}$ MES buffer to the fermentation medium and adjusting the $\mathrm{pH}$ 


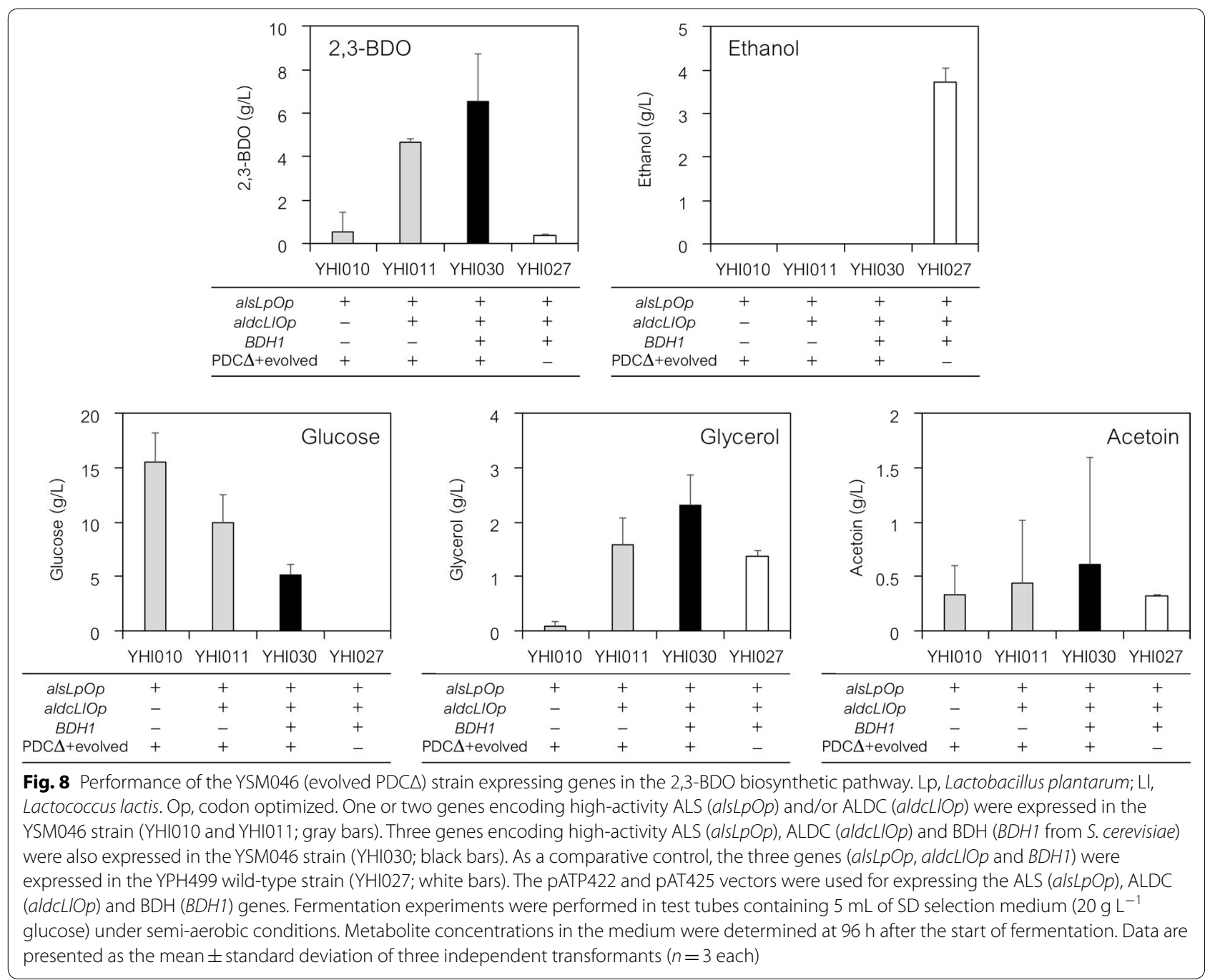

(See figure on next page.)

Fig. 9 2,3-BDO fermentation by the YHIO30 (evolved PDC $\triangle$ YSM046 expressing alsLpOp, aldcLIOp and BDH1) strain. After pre-cultivation, $0.75 \mathrm{~g}$-wet weight of cells were transferred into $50 \mathrm{~mL}$ of fresh SD selection media containing 25 (a), 50 (b) or 100 (c) $\mathrm{g} \mathrm{L}^{-1}$ glucose to give initial cell densities of $15 \mathrm{~g}$-wet cell weight $\mathrm{L}^{-1}$. Fermentation was conducted in small fermentation bottles with $\mathrm{CO}_{2}$ gas outlets under anaerobic (oxygen-limited) conditions. Data are presented as the mean \pm standard deviation of three separate cultivations ( $n=3$ each)

to 6.0, then conducting fermentation using milder agitation speeds (50, 100 and $150 \mathrm{rpm})$. We found that YHI030 strain rapidly and completely consumed $50 \mathrm{~g} \mathrm{~L}^{-1}$ glucose at each agitation speed tested (Additional file 1: Fig. S8). The cells produced approximately $14 \mathrm{~g} \mathrm{~L}^{-1} 2,3-\mathrm{BDO}$ and $5 \mathrm{~g} \mathrm{~L}^{-1}$ glycerol during fermentation conducted at 100 and $150 \mathrm{rpm}$ (Additional file 1: Fig. S8B and C), whereas at $50 \mathrm{rpm}$, the cells produced $17.6 \mathrm{~g} \mathrm{~L}^{-1} 2,3$-BDO but no significant reduction in glycerol was observed (Additional file 1: Fig. S8A). The cell density was increased $(\mathrm{OD}=25-28)$ and the $\mathrm{pH}$ was moderately decreased
$(\mathrm{pH}=3.5-4.5)$ during fermentation at 100 and $150 \mathrm{rpm}$ but remained essentially unchanged $(\mathrm{OD}=18-19$, $\mathrm{pH}=5.2-5.4)$ at $50 \mathrm{rpm}$.

YHI030 strain produced $34-39 \mathrm{~g} \mathrm{~L}^{-1}$ 2,3-BDO after 72-96 $\mathrm{h}$ of fermentation in $\mathrm{pH}$-adjusted buffered medium containing $100 \mathrm{~g} \mathrm{~L}^{-1}$ glucose (Additional file 1: Fig. S9). At $50 \mathrm{rpm}$, the glucose was almost entirely consumed at $72 \mathrm{~h}$ (Additional file 1: Fig. S9A), whereas more than $10-15 \mathrm{~g} \mathrm{~L}^{-1}$ glucose remained after $96 \mathrm{~h}$ of fermentation at 100 and $150 \mathrm{rpm}$ (Additional file 1: Fig. S9B and C). Similar to fermentation in the presence of $50 \mathrm{~g}$ 


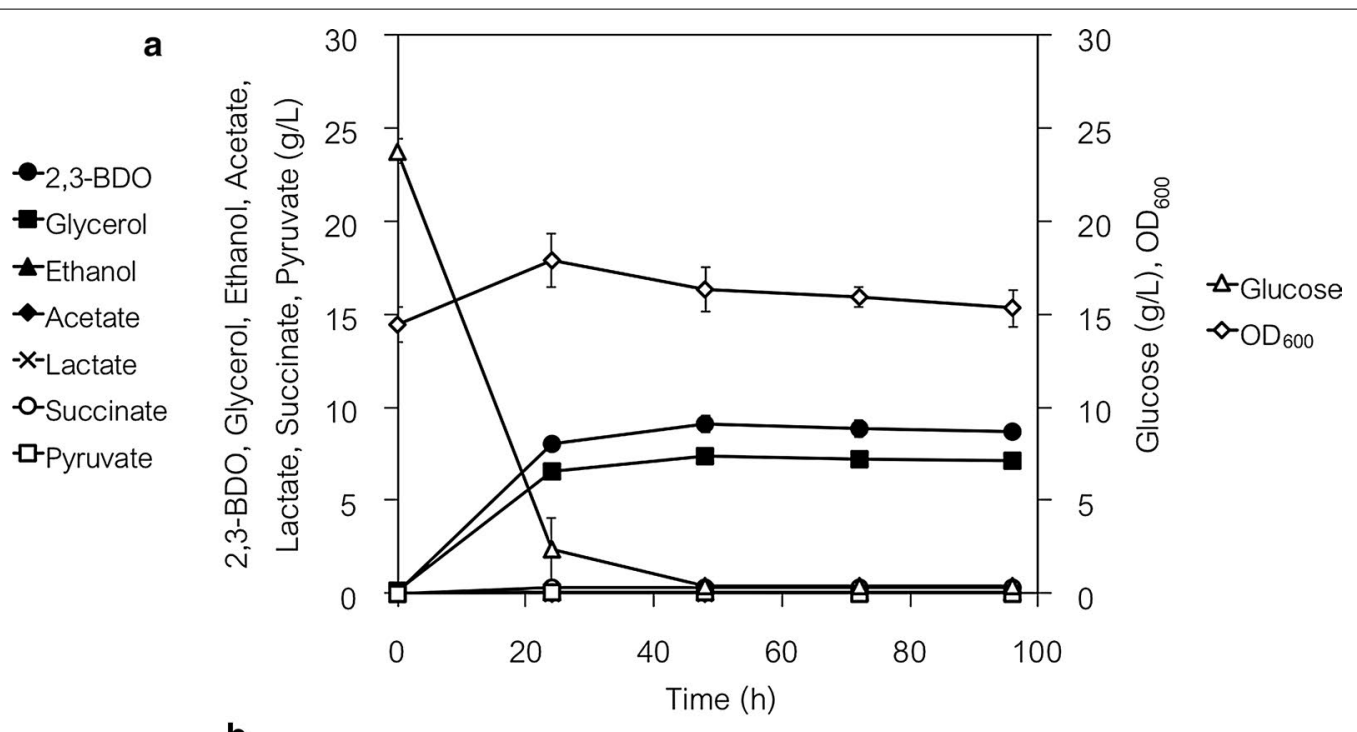

b

$-2,3-B D O$

-Glycerol

-Ethanol

-Acetate

-x-Lactate

- - Succinate

- Pyruvate

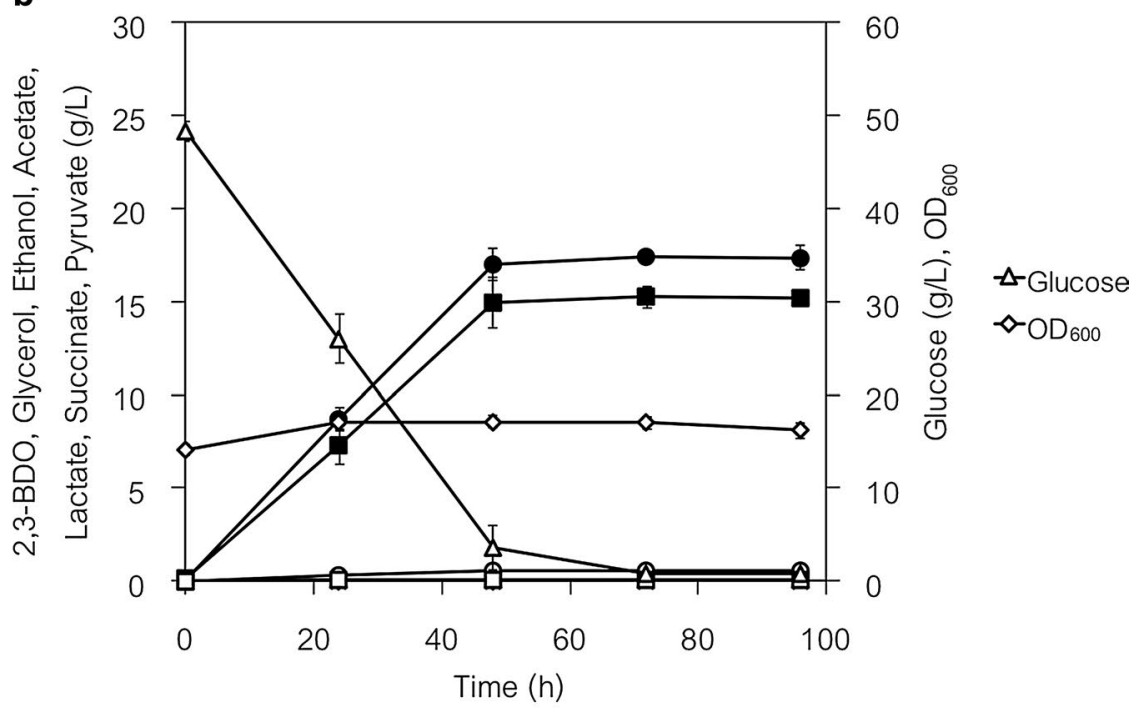

-2,3-BDO

-Glycerol

^Ethanol

-Acetate

$-x$-Lactate

-o-succinate

C

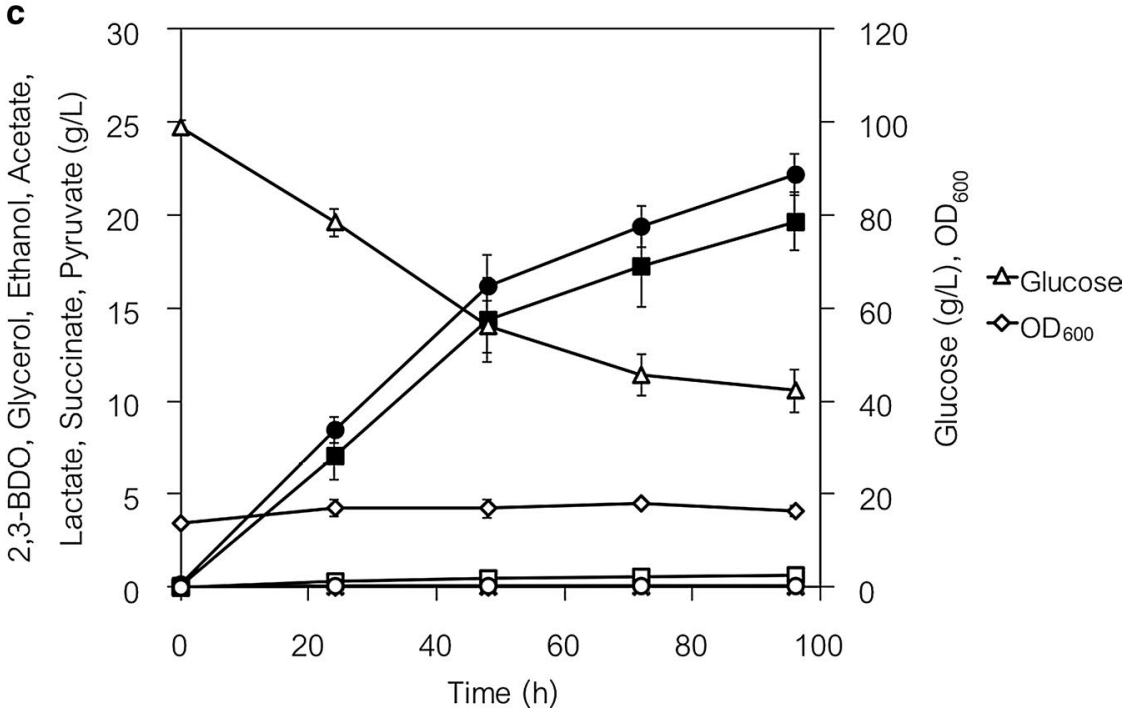


$\mathrm{L}^{-1}$ glucose, the cell density and $\mathrm{pH}$ of cultures agitated at $50 \mathrm{rpm}$ in the presence of $100 \mathrm{~g} \mathrm{~L}^{-1}$ glucose remained essentially constant whereas the cell densities of cultures agitated at 100 and $150 \mathrm{rpm}$ were increased and the $\mathrm{pH}$ values of the media were decreased.

\section{Fed-batch fermentation by YHI030 strain for the production of 2,3-BDO by adding a high concentration of glucose}

Finally, we again tested the step-by-step addition of glucose as the sole carbon source to medium buffered with $500 \mathrm{mM}$ MES (pH 6.0) (Fig. 10). During aerobic fermentation with 50-rpm agitation (mild aerobic conditions), $300 \mathrm{~g} \mathrm{~L}^{-1}$ glucose was added to the fermentation culture in three equal doses (100 $\mathrm{g} \mathrm{L}^{-1}$ each). YHI030 strain consumed the initial $100 \mathrm{~g} \mathrm{~L}^{-1}$ glucose and produced $36.2 \pm 1.7 \mathrm{~g} \mathrm{~L}^{-1} 2,3-\mathrm{BDO}$ at $72 \mathrm{~h}$ (Fig. 10). The cells consumed an additional $100 \mathrm{~g} \mathrm{~L}^{-1}$ glucose (total $200 \mathrm{~g}$ $\mathrm{L}^{-1}$ ) and produced $61.7 \pm 1.3 \mathrm{~g} \mathrm{~L}^{-1} 2,3-\mathrm{BDO}$ at $120 \mathrm{~h}$ after the first glucose addition (total $192 \mathrm{~h}$ ). Finally, the cells almost completely consumed a further additional $100 \mathrm{~g} \mathrm{~L}^{-1}$ glucose (total $300 \mathrm{~g} \mathrm{~L}^{-1}$ ) and the 2,3-BDO titer reached $81.0 \pm 1.3 \mathrm{~g} \mathrm{~L}^{-1}$ at $312 \mathrm{~h}$ after the second glucose addition (total $504 \mathrm{~h}$ ). The highest yield of 2,3-BDO in each (1st, 2nd and 3rd) fermentation step was 0.38 (at $72 \mathrm{~h}$ ), 0.35 (at $96 \mathrm{~h}$; total $168 \mathrm{~h}$ ), and 0.27 (at $312 \mathrm{~h}$; total $504 \mathrm{~h}) \mathrm{g} \mathrm{g} \mathrm{g}^{-1}$ glucose consumed. The glycerol titers were $32.3 \pm 0.7 \mathrm{~g} \mathrm{~L}^{-1}$ (at $72 \mathrm{~h}$ ), $55.3 \pm 0.7 \mathrm{~g} \mathrm{~L}^{-1}$ (at $120 \mathrm{~h}$; total $192 \mathrm{~h}$ ) and $71.8 \pm 0.7 \mathrm{~g} \mathrm{~L}^{-1}$ (at $312 \mathrm{~h}$; total $504 \mathrm{~h}$ ). The cells produced small amounts of succinate (1.3, 3.3 and $4.0 \mathrm{~g} \mathrm{~L}^{-1}$ ) and pyruvate (0.6, 1.0 and $1.0 \mathrm{~g} \mathrm{~L}^{-1}$ ) (at $72 \mathrm{~h}$, at $120 \mathrm{~h}$; total $192 \mathrm{~h}$, and at $312 \mathrm{~h}$; total $504 \mathrm{~h}$ ), but ethanol, acetate or lactate were not detected. The cell density remained essentially unchanged during the fermentation and $\mathrm{pH}$ gradually decreased to between $\mathrm{pH} 5$ and 6 (Fig. 10).

\section{Discussion}

The aim of this study was to develop a yeast metabolic engineering strategy for increasing higher alcohol production and concomitantly reducing ethanol subgeneration. To this end, we proposed a methodological approach for tugging the carbon flux in central metabolism at an important hub branching point (e.g., pyruvate and acetyl-CoA). We verified the validity of this strategy by testing 2,3-BDO production, which requires pyruvate as the hub branching point.

First, we ensured that pyruvate flux would be tugged towards 2,3-BDO biosynthesis by searching various ALS (acetolactate synthase) candidates to serve as the common first-step enzyme for the conversion of pyruvate to 2,3-BDO. We identified a high-activity ALS gene from $L$. plantarum (alsLp) by analyzing crude yeast cell extracts using an enzyme activity assay (Fig. 2). The high-activity alsLp gene was codon-optimized (alsLpOp) and its feasibility for 2,3-BDO production was tested. Expression of the alsLpOp gene in YPH499 wild-type strain resulted in a higher titer of 2,3-BDO production compared to the expression of other ALS genes, including endogenous yeast ILV2 (mitochondria) [4] and ILV2c (cytosol) [38] (Fig. 3a). Simple tuning of aeration and BDH expression resulted in a significant increase and decrease in 2,3$\mathrm{BDO}$ production and ethanol subgeneration, respectively (Fig. 3b, c). Thus, we validated the strategy of pyruvate carbon flux tugging using high-activity ALS for increasing higher alcohol production (2,3-BDO) in the wild-type strain.

However, substantial ethanol production was still observed and thus we generated the evolved PDC $\Delta$ YSM046 strain by quadruple deletions $(M T H 1-\Delta T$ allele and $P D C 1,5,6 \Delta$ ) and laboratory evolution. LC-MS/MS analysis was used to compare the pool sizes of glycolytic intermediates and cofactors (Fig. 7) and showed that YSM046 is a promising strain for the production of 2,3$\mathrm{BDO}$ and other compounds (e.g., lactate [44] and butanol [3]) because YSM046 significantly accumulated pyruvate and $\mathrm{NADH}$, the precursor and cofactor required for the biosynthesis of various metabolites [23, 45]. However, the specific growth rate of evolved PDC $\Delta$ strain YSM046 was $0.091 \pm 0.002 \mathrm{~h}^{-1}$ (from $20 \mathrm{~g} \mathrm{~L}^{-1}$ glucose under aerobic conditions), which is significantly slower than that of previously reported $\mathrm{Pdc}^{-}$strains with similar MTH1- $\triangle T$ alleles (cultured in aerobic, $\mathrm{pH}$-controlled bioreactors in medium containing $7.5 \mathrm{~g} \mathrm{~L}^{-1}$ glucose: $0.10 \mathrm{~h}^{-1}$ without evolution and $0.20 \mathrm{~h}^{-1}$ with evolution) $[40,46]$. The same $\mathrm{Pdc}^{-}$strains showed higher specific growth rates $\left(0.24\right.$ and $0.23 \mathrm{~h}^{-1}$, respectively) following the addition of a small amount of ethanol $(0.3 \%, v / v)$, whereas the original PDC-deficient yeast strain (without the MTH1- $\triangle T$ allele) could not grow in the presence of a high glucose

(See figure on next page.)

Fig. 10 2,3-BDO fermentation by the YHIO30 (evolved PDC $\triangle$ YSM046 expressing alsLpOp, aldcLIOp and BDH1) strain in pH-adjusted buffered medium under mild aerobic conditions. After pre-cultivation, $0.75 \mathrm{~g}$-wet weight of cells were transferred into $50 \mathrm{~mL}$ of fresh SD selection medium containing $100 \mathrm{~g} \mathrm{~L}^{-1}$ glucose and $500 \mathrm{mM} \mathrm{MES} \mathrm{(pH} \mathrm{adjusted} \mathrm{to} \mathrm{6.0)} \mathrm{to} \mathrm{give} \mathrm{initial} \mathrm{cell} \mathrm{densities} \mathrm{of} 15 \mathrm{~g}$-wet cell weight $\mathrm{L}^{-1}$. Fermentation was conducted in Erlenmeyer flasks under mild aerobic conditions. The agitation speed was $50 \mathrm{rpm}$. A total of $300 \mathrm{~g} \mathrm{~L}^{-1}$ of glucose was added to the fermentation culture in three equal doses $\left(100 \mathrm{~g} \mathrm{~L}^{-1}\right.$ each, including the initially contained glucose). Glucose was added to the fermentation culture at 72 and $192 \mathrm{~h}$. Data are presented as the mean \pm standard deviation of three separate cultivations $(n=3$ each) 

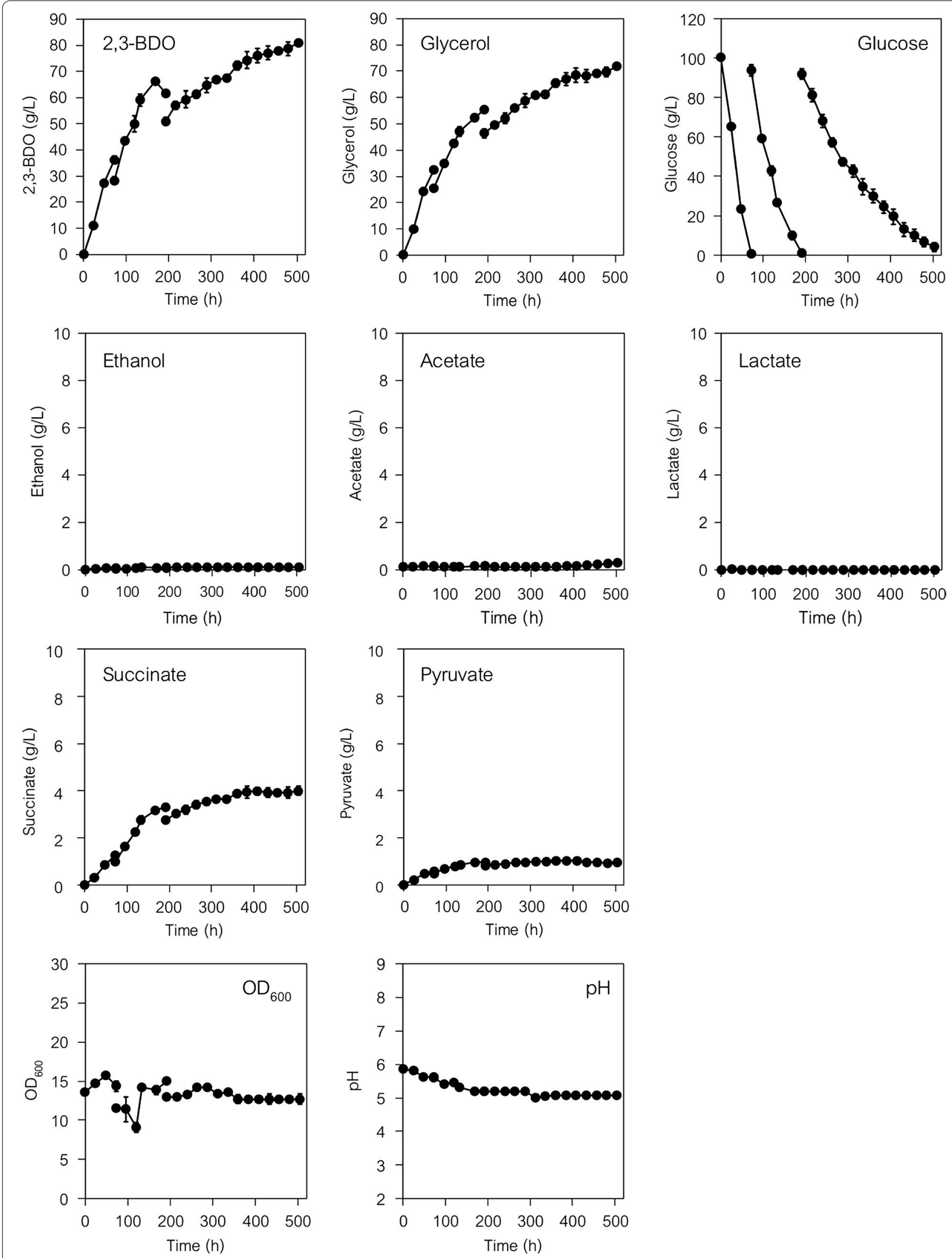
concentration as the sole carbon source and required C2 compounds (ethanol or acetate) for growth under low glucose concentrations. The necessity for $\mathrm{C} 2 \mathrm{com}-$ pounds may be due to the inability to synthesize cytosolic acetyl-CoA from pyruvate [40, 46-48]. Thus, the addition of $\mathrm{C} 2$ compounds might improve both cell growth and 2,3-BDO production by PDC $\Delta$ strains at high glucose concentrations.

YSM046 (evolved PDC $\Delta$ ) strain accumulated significant amounts of pyruvate (and NADH) and dramatically increased 2,3-BDO production by expressing alsLpOp, aldcLlOp and BDH1 (Fig. 8). In contrast to YPH499 wild-type strain (Additional file 1: Fig. S2), the additional expression of ALDC (acetolactate decarboxylase; aldcLlOp) by YSM046 strain substantially improved 2,3BDO productivity (Fig. 8). This evolved PDC $\Delta$ strain (YSM046) did not produce ethanol (Figs. 6 and 8) and thus the accumulated pyruvate (Fig. 7) could be used to consume glycolysis-derived NADH (or to regenerate $\mathrm{NAD}^{+}$). This excess pyruvate could be removed by converting 2-acetolactate to acetoin through spontaneous decarboxylation and subsequent reduction (via diacetyl) (Fig. 1b). This diacetyl pathway (Fig. 1b) is more balanced in terms of redox equilibrium than the ALDC pathway (Fig. 1c); however, the diacetyl pathway might have a limited capacity in 2-acetolactate conversion reaction. Consequently, expression of the ALDC enzyme likely aided the consumption of excess pyruvate during 2,3-BDO biosynthesis, despite the relatively poor redox balance (Fig. 1c).

The 2,3-BDO titer and yield of YHI030 strain (YSM046evolved PDC $\Delta$ strain expressing the alsLpOp, aldcLlOp and $B D H 1$ genes) were $6.6 \pm 2.2 \mathrm{~g} \mathrm{~L}^{-1}$ and $0.41 \mathrm{~g} \mathrm{~g}^{-1}$ consumed glucose, respectively. The 2,3-BDO titer generated by YHI030 strain was increased 17.8 -fold compared to YHI027 strain (and 20.5-fold based on consumed glucose) by introducing the PDC $\Delta$ genotype and through evolutionary engineering. These data clearly demonstrate the utility of our strategy using pyruvate flux tugging for 2,3-BDO production. In addition, this yield is comparable to the highest yield reported for an engineered $S$. cerevisiae strain $[12,26]$. In brief, the ADH- and NADdependent glycerol-3-phosphate dehydrogenase (GPD) enzymes were deleted from this previously reported

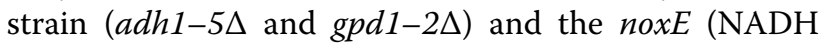
oxidase from Lactococcus lactis), alsS (ALS from Bacillus subtilis), alsD (ALDC from B. subtilis) and BDH1 (S. cerevisiae) genes were inserted. This strain achieved a high yield of 2,3-BDO $(72.9 \mathrm{~g} / \mathrm{L})$ at $0.41 \mathrm{~g} \mathrm{~g}^{-1}$ glucose consumed (fed-batch) by eliminating byproduct formation (GPD deletion) and redox rebalancing (noxE expression).

Finally, 2,3-BDO fermentation using a high density of YHI030 strain cells ( $15 \mathrm{~g} \mathrm{~L}^{-1}$; wet cell weight) and a high concentration of glucose as the sole carbon source was tested under various fermentation conditions (Figs. 9, 10, and Additional file 1: Figs. S6-S9). Under mild aerobic conditions (at an agitation of $50 \mathrm{rpm}$ ) in $\mathrm{pH}$-adjusted buffered medium, YHI030 strain completely consumed both 50 and $100 \mathrm{~g} \mathrm{~L}^{-1}$ glucose and, respectively, produced 17.6 and $37.2 \mathrm{~g} \mathrm{~L}^{-1} 2,3-\mathrm{BDO}$ (0.36 and $0.38 \mathrm{~g} \mathrm{~g}^{-1}$ glucose consumed) and glycerol (0.31 and $0.34 \mathrm{~g} \mathrm{~g}^{-1}$ glucose consumed) (Additional file 1: Figs. S8A and S9A). Fed-batch (consecutive addition) fermentation with $300 \mathrm{~g} \mathrm{~L}^{-1}$ glucose resulted in essentially complete consumption of the glucose and the production of $81.0 \pm 1.3 \mathrm{~g} \mathrm{~L}^{-1}$ 2,3-BDO (at $504 \mathrm{~h}$ ) (Fig. 10). Although $71.8 \pm 0.7 \mathrm{~g} \mathrm{~L}^{-1}$ glycerol was produced as a major by-product, no ethanol was detected.

In the near future, the subgeneration of abundant glycerol will be decreased by more elaborate control of fermentation conditions than simple aeration and $\mathrm{pH}$, and by genetic modifications such as expression of the noxE gene and deletion of the GPD1 and GPD2 genes, described previously $[26,49]$. Other ethanol-reducing yeast strains (e.g., with ADH deletions [26, 50-53] and various PDC modifications $[6,49,54])$ can also be used to further demonstrate our pyruvate carbon flux tugging strategy, in addition to the PDC $\Delta$ strain. Kim et al. recently reported a 2,3-BDO production level of $154.3 \mathrm{~g} \mathrm{~L}^{-1}$ by S. cerevisiae (fed-batch fermentation) with fine-tuned $P D C$ and noxE activities [54], and such strains might be compatible for further boosting 2,3-BDO production using our proposed strategy.

\section{Conclusions}

In this study, we demonstrated that a strategy for tugging carbon flux can increase 2,3-BDO production and reduce ethanol subgeneration in Crabtree-positive $S$. cerevisiae. A stronger pulling effect at the hub branching point (tug of carbon flux) was critical in our strategy. Pyruvate was chosen as an example of an important hub compound because it links to both the TCA cycle and amino acid biosynthesis. A high-activity ALS and PDC $\Delta$ strain was effective in exerting the pyruvate pulling effect, achieving a high titer of 2,3-BDO and no ethanol subgeneration. This strategy could be used for the production of other chemicals such as isobutanol and 3-methyl-1-butanol (via valine biosynthesis) [55-57].

\section{Additional files}

Additional file 1. Additional figures (Fig. S1-S9).

Additional file 2. Additional table (Table S1).

Additional file 3. Additional notes. This file includes Additional methods (Method S1-S9) and Additional results (Result S1 and S2). 


\begin{abstract}
Abbreviations
2-MPA: 2-methylpropanal (isobutyraldehyde); 2,3-BDO: 2,3-butanediol; ADH: alcohol dehydrogenase; ALDC: acetolactate decarboxylase; ALS: acetolactate synthase; alsLp: ALS gene from Lactobacillus plantarum; alsLPOp: codonoptimized alsLp gene; alsTf: ALS gene from Thermobifida fusca; alsTfOp: codon-optimized alsTf gene; BDH: butanediol dehydrogenase; CDS: coding DNA sequence; F6P: fructose 6-phosphate; FBP: fructose 1,6-bisphosphate; GPD: glycerol-3-phosphate dehydrogenase gene; HPLC: high-performance liquid chromatography; IGV: Integrative Genomics Viewer; ILV2c: the truncated version of the ILV2 gene lacking the mitochondrial signal sequence; ilVBEC: ALS gene from Escherichia coli; ilvBECOp: codon-optimized ilvBEC gene; LCMS/MS: liquid chromatography-tandem mass spectrometry; MEK: methyl ethyl ketone (butanone); MES: 2-(N-morpholino)ethanesulfonic acid; noxE: NADH oxidase gene; OD: optical density; PDC: pyruvate decarboxylase; PDC $\triangle$ : PDC-deficient yeast; SD: synthetic dextrose; SC: synthetic complete; SNP: single nucleotide polymorphism; TCA: tricarboxylic acid;YPDA: yeast-peptone-dextrose-adenine.
\end{abstract}

\section{Authors' contributions}

$\mathrm{Jl}$ and FM designed the research. Jl, KM, Kl, HK, SH and FM performed the experiments and analyzed data. SK acquired the metabolome data. KM carried out sample preparation and data analysis for genome re-sequencing. Jl, HS and FM interpreted the data. JI and FM wrote the manuscript. Jl, KI and FM participated in conception of the study. Jl, HS, AK, and FM co-coordinated this research project. All authors read and approved the final manuscript.

\section{Author details}

1 Graduate School of Science, Technology and Innovation, Kobe University, 1-1 Rokkodai, Nada, Kobe 657-8501, Japan. ${ }^{2}$ Department of Bioinformatic Engineering, Graduate School of Information Science and Technology, Osaka University, 1-5 Yamadaoka, Suita, Osaka 565-0871, Japan. ${ }^{3}$ Department of Chemical Science and Engineering, Graduate School of Engineering, Kobe University, 1-1 Rokkodai, Nada, Kobe 657-8501, Japan. ${ }^{4}$ RIKEN Center for Sustainable Resource Science, 1-7-22 Suehiro, Tsurumi, Yokohama 230-0045, Japan.

\section{Acknowledgements}

Data acquisition by the next-generation sequencer was supported by Prof. Yuu Hirose (Toyohashi University of Technology, Japan). Plasmid vectors (pGK425 and pAT425) were provided by the National Bio-Resource Project (NBRP), Japan.

\section{Competing interests}

The authors declare that they have no competing interests.

\section{Availability of data and materials}

The datasets supporting the conclusions of this article are included within the article and its additional files.

\section{Consent for publication}

Not applicable.

\section{Ethics approval and consent to participate}

Not applicable.

\section{Funding}

This work was supported by the Industrial Technology Research Grant Program for 2011 of the New Energy and Industrial Technology Development Organization (NEDO); a Grant-in-Aid for Scientific Research (C) no. 15 K06579 and 18K04851; a JST-Mirai Program Grant Number JPMJMI17EJ; and the Special Coordination Funds for Promoting Science and Technology, Creation of Innovation Centers for Advanced Interdisciplinary Research Areas (Innovative Bioproduction Kobe; iBioK) from the Ministry of Education, Culture, Sports, Science and Technology (MEXT) of Japan.

\section{Publisher's Note}

Springer Nature remains neutral with regard to jurisdictional claims in published maps and institutional affiliations.

Received: 22 February 2018 Accepted: 16 June 2018

Published online: 26 June 2018

\section{References}

1. Steensels J, Snoek T, Meersman E, Picca Nicolino M, Voordeckers K, Verstrepen KJ. Improving industrial yeast strains: exploiting natural and artificial diversity. FEMS Microbiol Rev. 2014;38:947-95.

2. Nishimura Y, Matsui T, Ishii J, Kondo A. Metabolic engineering of the 2-ketobutyrate biosynthetic pathway for 1-propanol production in Saccharomyces cerevisiae. Microb Cell Fact. 2018;17:38.

3. Steen EJ, Chan R, Prasad N, Myers S, Petzold CJ, Redding A, Ouellet M, Keasling JD. Metabolic engineering of Saccharomyces cerevisiae for the production of n-butanol. Microb Cell Fact. 2008;7:36.

4. Kondo T, Tezuka H, Ishii J, Matsuda F, Ogino C, Kondo A. Genetic engineering to enhance the Ehrlich pathway and alter carbon flux for increased isobutanol production from glucose by Saccharomyces cerevisiae. J Biotechnol. 2012;159:32-7.

5. Rao Z, Ma Z, Shen W, Fang H, Zhuge J, Wang X. Engineered Saccharomyces cerevisiae that produces 1,3-propanediol from D-glucose. J Appl Microbiol. 2008;105:1768-76.

6. Kim SJ, Seo SO, Jin YS, Seo JH. Production of 2,3-butanediol by engineered Saccharomyces cerevisiae. Bioresour Technol. 2013;146:274-81.

7. Lian JZ, Chao R, Zhao HM. Metabolic engineering of a Saccharomyces cerevisiae strain capable of simultaneously utilizing glucose and galactose to produce enantiopure (2R,3R)-butanediol. Metab Eng. 2014:23:92-9.

8. Kim SJ, Seo SO, Park YC, Jin YS, Seo JH. Production of 2,3-butanediol from xylose by engineered Saccharomyces cerevisiae. J Biotechnol. 2014;192:376-82.

9. $\mathrm{Nan} \mathrm{H}$, Seo SO, Oh EJ, Seo JH, Cate JHD, Jin YS. 2,3-Butanediol production from cellobiose by engineered Saccharomyces cerevisiae. Appl Microbiol Biotechnol. 2014;98:5757-64.

10. Bialkowska AM. Strategies for efficient and economical 2,3-butanediol production: new trends in this field. World J Microbiol Biotechnol. 2016;32:200.

11. Xu Y, Chu H, Gao C, Tao F, Zhou Z, Li K, Li L, Ma C, Xu P. Systematic metabolic engineering of Escherichia coli for high-yield production of fuel bio-chemical 2,3-butanediol. Metab Eng. 2014;23:22-33.

12. Kim SJ, Kim JW, Lee YG, Park YC, Seo JH. Metabolic engineering of Saccharomyces cerevisiae for 2,3-butanediol production. Appl Microbiol Biotechnol. 2017;101:2241-50.

13. Song D, Yoon YG, Lee CJ. Conceptual design for the recovery of 1,3-Butadiene and methyl ethyl ketone via a 2,3-Butanediol-dehydration process. Chem Eng Res Des. 2017;123:268-76.

14. Zheng QX, Wales MD, Heidlage MG, Rezac M, Wang HW, Bossmann SH, Hohn KL. Conversion of 2,3-butanediol to butenes over bifunctional catalysts in a single reactor. J Catal. 2015;330:222-37.

15. Lynch J. BD monomer and elastomer production processes. Chem Biol Interact. 2001;135:147-53.

16. Maji T, Mendis $\mathrm{CH}$, Thompson WH, Tunge JA. Evidence for isomerizing hydroformylation of butadiene. A combined experimental and computational study. J Mol Catal A Chem. 2016;424:145-52.

17. Zellmer $L$. The 100 most important chemical compounds: a reference guide. Libr J. 2007;132:158.

18. Stytsenko VD, Mel'nikov DP. Selective hydrogenation of dienic and acetylenic compounds on metal-containing catalysts. Russ J Phys Chem A. $2016 ; 90: 932-42$.

19. Ishii J, Tominaga M, Nishida K, Matsuda F, Nishi T, Hasunuma T, Moriya $H$, Kuriya Y, Araki M, Hara KY, et al. Synthetic bioengineering: a more intensely engineering-conscious sub-discipline of synthetic biologydrawing upon a SynBio toolbox and yeast metabolic engineering. 2018. under revision.

20. Hagman A, Piskur J. A study on the fundamental mechanism and the evolutionary driving forces behind aerobic fermentation in yeast. PLoS ONE. 2015;10:e0116942.

21. Kajihata S, Matsuda F, Yoshimi M, Hayakawa K, Furusawa C, Kanda A, Shimizu H. ${ }^{13} \mathrm{C}$-based metabolic flux analysis of Saccharomyces cerevisiae with a reduced Crabtree effect. J Biosci Bioeng. 2015;120:140-4.

22. Simeonidis E, Murabito E, Smallbone K, Westerhoff HV. Why does yeast ferment? A flux balance analysis study. Biochem Soc Trans. 2010;38:1225-9.

23. Vemuri GN, Eiteman MA, McEwen JE, Olsson L, Nielsen J. Increasing NADH oxidation reduces overflow metabolism in Saccharomyces cerevisiae. Proc Natl Acad Sci USA. 2007;104:2402-7. 
24. Matsuda F, Furusawa C, Kondo T, Ishii J, Shimizu H, Kondo A. Engineering strategy of yeast metabolism for higher alcohol production. Microb Cell Fact. 2011;10:70.

25. Ryan ED, Kohlhaw GB. Subcellular localization of isoleucine-valine biosynthetic enzymes in yeast. J Bacteriol. 1974;120:631-7.

26. Kim S, Hahn JS. Efficient production of 2,3-butanediol in Saccharomyces cerevisiae by eliminating ethanol and glycerol production and redox rebalancing. Metab Eng. 2015;31:94-101.

27. Sikorski RS, Hieter P. A system of shuttle vectors and yeast host strains designed for efficient manipulation of DNA in Saccharomyces cerevisiae. Genetics. 1989;122:19-27.

28. Akada R, Kitagawa T, Kaneko S, Toyonaga D, Ito S, Kakihara Y, Hoshida H, Morimura S, Kondo A, Kida K. PCR-mediated seamless gene deletion and marker recycling in Saccharomyces cerevisiae. Yeast. 2006;23:399-405.

29. Gietz D, Stjean A, Woods RA, Schiestl RH. Improved method for high-efficiency transformation of intact yeast-cells. Nucleic Acids Res. 1992;20:1425.

30. Langmead B, Salzberg SL. Fast gapped-read alignment with Bowtie 2. Nat Methods. 2012;9:357-9.

31. Li H, Handsaker B, Wysoker A, Fennell T, Ruan J, Homer N, Marth G, Abecasis G, Durbin R. Genome project data processing S. The sequence alignment/map format and SAMtools. Bioinformatics. 2009;25:2078-9.

32. Robinson JT, Thorvaldsdottir H, Winckler W, Guttman M, Lander ES, Getz G, Mesirov JP. Integrative genomics viewer. Nat Biotechnol. 2011;29:24-6.

33. Singh BK, Stidham MA, Shaner DL. Assay of acetohydroxyacid synthase. Anal Biochem. 1988;171:173-9.

34. Lee YT, Duggleby RG. Mutations in the regulatory subunit of yeast acetohydroxyacid synthase affect its activation by MgATP. Biochem J. 2006;395:331-6.

35. Nishino S, Okahashi N, Matsuda F, Shimizu H. Absolute quantitation of glycolytic intermediates reveals thermodynamic shifts in Saccharomyces cerevisiae strains lacking PFK1 or ZWF1 genes. J Biosci Bioeng. 2015;120:280-6.

36. Renna MC, Najimudin N, Winik LR, Zahler SA. Regulation of the Bacillus subtilis alsS, alsD, and alsR genes involved in post-exponential-phase production of acetoin. J Bacteriol. 1993;175:3863-75.

37. Ishii J, Izawa K, Matsumura S, Wakamura K, Tanino T, Tanaka T, Ogino C, Fukuda $\mathrm{H}$, Kondo A. A simple and immediate method for simultaneously evaluating expression level and plasmid maintenance in yeast. J Biochem. 2009;145:701-8.

38. Matsuda F, Kondo T, Ida K, Tezuka H, Ishii J, Kondo A. Construction of an artificial pathway for isobutanol biosynthesis in the cytosol of Saccharomyces cerevisiae. Biosci Biotechnol Biochem. 2012;76:2139-41.

39. Ishii J, Kondo T, Makino H, Ogura A, Matsuda F, Kondo A. Three gene expression vector sets for concurrently expressing multiple genes in Saccharomyces cerevisiae. FEMS Yeast Res. 2014;14:399-411.

40. Oud B, Flores CL, Gancedo C, Zhang X, Trueheart J, Daran JM, Pronk JT, van Maris AJ. An internal deletion in MTH1 enables growth on glucose of pyruvate-decarboxylase negative, non-fermentative Saccharomyces cerevisiae. Microb Cell Fact. 2012;11:131.

41. Schneider R, Brors B, Burger F, Camrath S, Weiss H. Two genes of the putative mitochondrial fatty acid synthase in the genome of Saccharomyces cerevisiae. Curr Genet. 1997;32:384-8.

42. Moriya H, Shimizu-Yoshida Y, Omori A, Iwashita S, Katoh M, Sakai A. Yak1p, a DYRK family kinase, translocates to the nucleus and phosphorylates yeast Pop2p in response to a glucose signal. Genes Dev. 2001;15:1217-28.
43. Garrett S, Menold MM, Broach JR. The Saccharomyces cerevisiae YAK1 gene encodes a protein kinase that is induced by arrest early in the cell cycle. Mol Cell Biol. 1991;11:4045-52.

44. Colombie S, Dequin S, Sablayrolles JM. Control of lactate production by Saccharomyces cerevisiae expressing a bacterial LDH gene. Enzyme Microbial Technol. 2003;33:38-46.

45. Cordova LT, Alper HS. Central metabolic nodes for diverse biochemical production. Curr Opin Chem Biol. 2016;35:37-42.

46. van Maris AJ, Geertman JM, Vermeulen A, Groothuizen MK, Winkler AA, Piper MD, van Dijken JP, Pronk JT. Directed evolution of pyruvate decarboxylase-negative Saccharomyces cerevisiae, yielding a C2-independent, glucose-tolerant, and pyruvate-hyperproducing yeast. Appl Environ Microbiol. 2004;70:159-66.

47. Flikweert MT, Van Der Zanden L, Janssen WM, Steensma HY, Van Dijken JP, Pronk JT. Pyruvate decarboxylase: an indispensable enzyme for growth of Saccharomyces cerevisiae on glucose. Yeast. 1996;12:247-57.

48. Flikweert MT, de Swaaf M, van Dijken JP, Pronk JT. Growth requirements of pyruvate-decarboxylase-negative Saccharomyces cerevisiae. FEMS Microbiol Lett. 1999;174:73-9.

49. Kim JW, Seo SO, Zhang GC, Jin YS, Seo JH. Expression of Lactococcus lactis $\mathrm{NADH}$ oxidase increases 2,3-butanediol production in Pdc-deficient Saccharomyces cerevisiae. Bioresour Technol. 2015;191:512-9.

50. Ida Y, Furusawa C, Hirasawa T, Shimizu H. Stable disruption of ethanol production by deletion of the genes encoding alcohol dehydrogenase isozymes in Saccharomyces cerevisiae. J Biosci Bioeng. 2012;113:192-5.

51. Ida Y, Hirasawa T, Furusawa C, Shimizu H. Utilization of Saccharomyces cerevisiae recombinant strain incapable of both ethanol and glycerol biosynthesis for anaerobic bioproduction. Appl Microbiol Biotechnol. 2013;97:4811-9.

52. Hirasawa T, Ida Y, Furusawa C, Shimizu H. Potential of a Saccharomyces cerevisiae recombinant strain lacking ethanol and glycerol biosynthesis pathways in efficient anaerobic bioproduction. Bioengineered. 2014;5:123-8.

53. Tokuhiro K, Ishida N, Nagamori E, Saitoh S, Onishi T, Kondo A, Takahashi H. Double mutation of the PDC1 and $A D H 1$ genes improves lactate production in the yeast Saccharomyces cerevisiae expressing the bovine lactate dehydrogenase gene. Appl Microbiol Biotechnol. 2009;82:883-90.

54. Kim JW, Kim J, Seo SO, Kim KH, Jin YS, Seo JH. Enhanced production of 2,3-butanediol by engineered Saccharomyces cerevisiae through fine-tuning of pyruvate decarboxylase and NADH oxidase activities. Biotechnol Biofuels. 2016;9:265.

55. Atsumi S, Hanai T, Liao JC. Non-fermentative pathways for synthesis of branched-chain higher alcohols as biofuels. Nature. 2008;451:86-9.

56. Matsuda F, Ishii J, Kondo T, Ida K, Tezuka H, Kondo A. Increased isobutanol production in Saccharomyces cerevisiae by eliminating competing pathways and resolving cofactor imbalance. Microb Cell Fact. 2013;12:119.

57. Park SH, Kim S, Hahn JS. Metabolic engineering of Saccharomyces cerevisiae for the production of isobutanol and 3-methyl-1-butanol. Appl Microbiol Biotechnol. 2014;98:9139-47.

Ready to submit your research? Choose BMC and benefit from:

- fast, convenient online submission

- thorough peer review by experienced researchers in your field

- rapid publication on acceptance

- support for research data, including large and complex data types

- gold Open Access which fosters wider collaboration and increased citations

- maximum visibility for your research: over $100 \mathrm{M}$ website views per year

At BMC, research is always in progress.

Learn more biomedcentral.com/submissions 